\title{
The Drawing and Perception of Architectural Spaces through Immersive Virtual Reality
}

\author{
Hugo C. Gómez-Tone ${ }^{1, *(\mathbb{C})}$, John Bustamante Escapa ${ }^{1}$ (), Paola Bustamante Escapa ${ }^{1}$ \\ and Jorge Martin-Gutierrez ${ }^{2}$ (D) \\ 1 Academic Department of Architecture, Universidad Nacional de San Agustín de Arequipa, \\ 04002 Arequipa, Peru; jbustamantee@unsa.edu.pe (J.B.E.); pbustamantees@unsa.edu.pe (P.B.E.) \\ 2 Department of Techniques and Projects in Engineering and Architecture, Universidad de La Laguna, \\ 38071 Tenerife, Spain; jmargu@ull.edu.es \\ * Correspondence: hgomezt@unsa.edu.pe
}

\section{check for}

updates

Citation: Gómez-Tone, H.C.; Bustamante Escapa, J.; Bustamante Escapa, P.; Martin-Gutierrez, J. The Drawing and Perception of Architectural Spaces through Immersive Virtual Reality. Sustainability 2021, 13, 6223. https://doi.org/10.3390/su13116223

Academic Editors: David

Fonseca Escudero and Mónica

Vanesa Sánchez-Sepúlveda

Received: 8 March 2021

Accepted: 21 May 2021

Published: 1 June 2021

Publisher's Note: MDPI stays neutral with regard to jurisdictional claims in published maps and institutional affiliations.

Copyright: (c) 2021 by the authors. Licensee MDPI, Basel, Switzerland. This article is an open access article distributed under the terms and conditions of the Creative Commons Attribution (CC BY) license (https:// creativecommons.org/licenses/by/ $4.0 /)$.

\begin{abstract}
The technologies that have sought to intervene in the architectural drawing process have focused on the sense of sight, leaving aside the use of the hands and the entire body that together achieve more sensory designs. Nowadays, to the benefit of the draftsman, that ideal scenery in which sight, hands and body work holistically is returning thanks to Immersive Virtual Reality (IVR). The purpose of this research is to analyze the perception of two-dimensionally drawn spaces, the drawing of such spaces through three-dimensional sketches in IVR, and both the perception of 3D sketched spaces and those which are also modeled realistically in IVR. First and fifth year architecture students went through the four phases of the experiment: (a) the perception of a space based on 2D sketches, (b) real-scale 3D space drawing in IVR, (c) the perception of a space drawn in 3D in IVR, and (d) the perception of the same space realistically modeled in 3D in IVR. Through three questionnaires and a grading sheet, the data was obtained. The perception of two-dimensionally drawn spaces was high $(70.8 \%)$, while the precision of a space drawn in an IVR was even higher (83.9\%). The real or natural scale in which the spaces can be experienced in an IVR is the characteristic that was most recognized by the students; however, this and the other qualities did not allow for a reliable conclusion for a homogeneous perception of sensations within the virtual spaces.
\end{abstract}

Keywords: immersive virtual reality; drawing; architecture; perception; HMD; sketches

\section{Introduction}

Architecture students must learn to imagine and build in their minds the architectural spaces they are designing; however, the mind is not capable of sustaining such designs in their totality and complexity; it is here that rapid freehand drawings are used by architects and designers to hold designs in front of their eyes. This inevitably frees the mind of such a burden and gives the sense of sight the ability to examine and evaluate the design. Thus, sketches alleviate the burden of the short-term memory, requiring coherence and increasing information processing [1]. Likewise, creative ideas arrive in an instant as a wave of thought, and in many cases they disappear in the same instant. For this reason, it is necessary, in the creative development of the future architect, to know how to capture and communicate those creative ideas quickly with quick freehand drawings [2]. Although it may seem to some that these quick and ambiguous drawings do not contribute to the design process, some researchers have shown that ambiguity in design sketches is a source of creativity, rather than uncertainty or confusion [3]. This is because it allows us to reconsider and reinterpret what is designed, thus achieving new relationships and perceptual configurations in a sketch, which generate a creative productive cycle [4].

Despite the proven importance of freehand drawing, two problems have arisen in the last three decades that have affected the way the student should draw. The first is that drawing topics are still maintained in universities as an introductory class, without clearly 
differentiating between mimetic drawing (learning drawing by observation and imitation) and non-representative drawing which is properly configurative and conceptual [5], and which implies learning to draw and project at the same time. As a consequence, it forces an understanding between the graphic language and the projective process and allows for the acquisition of a new operative that is comprehensive and executes habits, not only learning to draw as a mere propaedeutic discipline [6]. The second problem is the incorporation of the computer technologies applied to architectural drawing that have ended up moving the hands of the draftsman towards the keyboard and mouse of a computer to make the drawings, creating the so-called "informatic hand" [7] which blurs the links between architect, freehand sketch, and design.

Despite the dilemmas in its conceptualization and the negative influence of technologies on freehand drawing, it is possible to reevaluate the use of technology in drawing. For instance, another emerging technology, immersive virtual reality (IVR), is returning to the student and the architect the mastery of the "thinking hand" and the whole body through freehand drawing using haptic controllers, but this time in three dimensions in a virtual and immersive world.

\subsection{The Importance of Sketches in Architecture}

In addition to the previously mentioned information, sketches are important as a means of expression and communication. They are the vehicle that allows students and architects to design and project visually beautiful spaces which are rich in sensory experiences that impact the public in an unforgettable way, and that create memories and experiences that capture their tactile, auditory and even olfactory sensations [8]. This is due to the phenomenon called "affordance", understood as the behavioral potentialities offered by a built environment for people (a concept extracted from the psychology of perception and behavior) [9]. This explains how an architectural space can be perceived and experienced even if the person is not in front of it or physically in its vicinity. This is to say that spaces can be perceived based on the observation of drawings or sketches because they have the ability to stimulate the observer to experience new spatial realities, allowing them to experience the represented space as if it were a real one, being able to walk, look, enter, leave, touch, feel the temperature, and smell, etc. [10,11], hence the importance of drawing as a physical product in the design process of architects, and even more so in architecture students.

Another characteristic that makes sketches important in architecture is in the initial and conceptual stages of the design process. This includes their ease and speed of execution, which puts them ahead of other means of communication such as computer drawing tools or physical models that are built on smaller scales, which are difficult to modify during communication or design debate. Additionally, they present difficulties in observing the interior of spaces [12].

Furthermore, the increasing complexity of architecture makes it difficult to use sketches when it comes to complex spaces that are difficult to imagine, understand and present, and which are therefore difficult to perceive [13]. Consequently, in order to evaluate the human spatial experience, sensations, and functional relationships of spaces, designers have no choice but to use three-dimensional models built by computer (CAD), but these show limitations in the perception of spaces due to problems of the scale and distance of the model presented on a computer monitor, despite its many proven advantages.

\subsection{The Importance of the Action of Drawing with the Hand}

The title of the book 'The Thinking Hand' [14] reminds us of the importance of the "feeling" hand and body that structure our relationships with the world, and that in each learned activity, such as art and architecture, make up a modality of thought comprised of drawings and images created by hands, in which the body of the draftsman becomes the place of drawing, and the task of doing it is lived before it is understood. All of the primary sensations learned through experience are reproduced in the intention set when 
painting, drawing and modeling; in this way, the architect relives all primitive experiences by modeling surfaces with his hands, creating enveloping spaces around the body in order to live in them and not simply look at them [15].

Architecture, understood as the construction of places, as the action of extending the inner world of people to the outer world, and as the creation of forms capable of being experienced and lived, leads us to consider that in the design process, we cannot depend solely on of the sense of sight without taking into account the rest of the senses. We need the hands and the whole body to give authenticity to the designed architecture [6].

If we consider the sense of sight as the dominant element in architectural design (ocularcentrism), we will seek to ignore the physical and psychological relationship created between the subject and space during the spatial experience, sensual memory, movement, and time. However, the act of touching, that is, the interaction between architecture and the subject dependent on physical and cognitive perception, offers another way of thinking and interpreting architecture, constituting an alternative starting point for design [16], which we must seek to achieve in architectural designs that not only respond to man's basic needs, but also to his emotional wellbeing.

The process of drawing with the hands allows us to externalize the mental models and concepts of the designer. In addition, the action of drawing allows us to discover new links and approaches to obtain new characteristics of what is designed, which has a crucial importance in the conceptual phase of design [17]. What makes the relationship between drawing and the action of drawing so important is that an action is generated that involves not only sight but also other senses, specifically those that are found in the corporeal and unconscious memory of the individual. Furthermore, it involves various mental and cognitive processes and imaginings that are not only very difficult replace with technological tools, such as modeling programs and computer-aided drawing, but can also distort this relationship between the action of drawing and cognitive processes [10].

\subsection{The Perception of Architectural Spaces in IVR}

The way in which we humans perceive the space that surrounds us has many aspects rooted in the psychology of perception. The understanding of the environment involves factors ranging from visual physiology to cultural and social aspects. We could define this process as that which makes a person conscious of the relative position of his or her own body in relation to surrounding objects, and the relations to them in terms of distance, size and orientation, as is necessary to allow him to move in his environment [18].

The two main cues for understanding space are the perception of distance and depth. As previously stated, this data is acquired through various sensorial channels that, at a perceptual level, render different measures that are cross-linked to extract relevant information. We always perceive while our brain registers external information. We perceive when we see, smell, touch, feel cold or heat, hear, or taste, and it is these senses that allow us to have perceived sensations.

If we refer to the sense of sight, visual perception is the interpretation or discrimination of external visual stimuli related to prior knowledge and the emotional state of the individual. Thus, visual perception allows us to create and recreate in a sensitive and automatic way the information that the architect wishes to capture in a project. It also allows him to express his feelings, emotions and perceptions of the architectural space. Each sense identifies different qualities of the space to be perceive. Sight and hearing allow us to establish a broader relationship to distant experiences. On the other hand, touch, smell and taste are capable of perceiving the closest qualities [19]. Perception is related with the corporeal relationship of the human being who experiences a space, and with the cultural, social and psychological conditions that surround him.

In the field of computer graphics, the perception of space requires the introduction of the concept of immersion provided by virtual reality. Although it is possible to describe space by way of simulated movement around virtual models on a computer screen, the sense of presence in space requires the viewer to feel himself to be inside it, immersed. 
Immersive virtual reality environments which use high resolution Head Mounted Displays (HMD) can provide a real-scale perception of spaces and a precision in the representation of materiality which, together with the control tools for navigation in the environment, give it a greater sense of presence to simulate architectural experiences and obtain a sensory perception of spaces in real time [20]. However, this technology can not only improve spatial perception and improve design but can also affect the design process and provide changes in the way of thinking of architectural design, allowing designers to incorporate human experience into the design process and drawing [13].

One of the most desired challenges in architecture is to be able to measure the perception that the design of a given space provides to the user. Virtual reality provides an immersive environment in which a participant can experience a sense of presence so strong and comparable to real life that it generates emotional responses, with physiological changes in heart rate, respiration, blood pressure and the galvanic response of the skin, and even changes in brain electrophysiology [21]. These can serve as indicators to measure human emotional experiences in architectural spaces [22,23], which would the quantification, in a more objective way, of the sensations and emotions perceived in the architectural spaces. These studies support the idea that virtual environments, in combination with virtual reality, could be considered as an alternative method when investigating the impact of stimuli that the characteristics of the space can cause [24-26].

Despite the technological advances and research to quantify the perception of sensations and emotions, the truth is that they are not capable of providing practical guidelines and criteria for architects and designers to incorporate emotions into their designs [27]. The impact of architecture on emotions and the multisensory analysis applied in this field is complex in nature, and most research concludes that, in order to accurately measure sensations and emotions, it is necessary to combine objective tests such as those mentioned above with subjective tests such as surveys, questionnaires, or interviews.

In addition, the perception of space can be affected by at least two cognitive processes reported so far: the estimation of distances, and mobility and orientation in virtual worlds. Mental representations of space that are based on the knowledge of the defining elements of space and the spatial relationship between those elements require the evaluation of the distances between pairs of spatial elements. Locomotion techniques in virtual immersive environments, such as artificial locomotion and teleportation, affect the way in which virtual environments are perceived due to the underestimation of distances. However, simple training allows people to improve their distance estimates [28]. In addition, it has been reported that the technique of virtual walking offers the greatest immersion, but also presents high levels of psychophysical distress, while teleportation is considered effective due to its fast navigation, but its visual "jumps" break the sensation of immersion of users, affecting their perception [29]. It is considered that, for navigation and orientation purposes, virtual models should not show too much information or realism, which distracts the users [30].

\subsection{The Virtual Drawing}

After three decades of technological advances in the field of graphic representation for architecture and engineering, the bond of the draftsman and the action of drawing are once again converging to the visual and the haptic. This is causing the principles of drawing to change their focus, from two-dimensional immersion to three-dimensional immersion, achieving cognitive experiences that express the interaction of the participants with simulated environments [31]. On the other hand, virtual reality technologies have been significantly improved and have expanded the possibilities for the presentation of architectural concepts thanks to powerful software and hardware functionalities. Yang and Lee [32] have shown that three-dimensional sketches in IVR help designers to reduce their dependence on external representations and improve their mental processing for the transformation and consolidation of their ideas, in addition to extending the solution spaces and having a positive effect on the building of holistic design thinking, which 
focuses on systematic progression in the overall design concept and the harmonization of both aesthetic and functional goal setting strategies. IVR allows designers to create new points of view through the immersive experience, and the ability to walk around three-dimensional sketches [33]. Some researchers have highlighted the positive effect of VR-based design that takes a qualitative leap when developing design solutions in the same creative process [34], and other researchers have integrated the key attributes of hand drawing into a new medium of virtual reality for design [35].

Within the field of the education of architecture, the student must be able, first of all, to perceive and interpret drawings and sketches, not only in more precise ways but in more sensorial ways, responding to a crucial requirement, i.e., the possession of a special sensitivity to the natural and built environment. Secondly, they must be able to make quick freehand drawings, making them a tool for creative thinking. From the sketches and the action of drawing by hand, it is possible to travel the path and accompany the ideas and concepts until they are incorporated into the physical and real world. This process, in which the actions of thinking, drawing, and building follow each other continuously, and working with the hands in a conscious way, leads us to develop a thought operation in which the eyes and the hands work together. During the design process, it is necessary for the student to learn how to work with the hands and use the appropriate instruments and tools, trying to minimize the importance of obtaining projections or mechanical representations of architectural objects, in order to focus on the being of things, in their presence or in their being present [36].

Despite today's teachers not being equipped to face an education that is being technologically updated every day towards a futuristic perspective [37] and university study plans not being adapted to current technological needs [38], this educational paradigm of the drawing and perception of architectural spaces will be overcome in a natural way with IVR and the use of the hands and the body, as previously discussed, in drawing and architectural designs.

\subsection{Research Purpose}

Although several investigations are currently demonstrating the benefits of the use of IVR, in the professional and pedagogical field of architecture [11,39] there are few lines of research that analyze the benefits and disadvantages of the three-dimensional sketch of architectural spaces as a final product that communicates design ideas, and as an action of drawing and designing that is so important for the architect. Likewise, although there are experiences of the direct measurement of emotions in architectural spaces using devices that measure physiological and cognitive parameters [26], it is important that students express and recognize the sensations perceived in architectural spaces. Knowing that these perceptions are key in architectural design, because spaces are designed for a specific use, and those constructed spaces must evoke in the user emotions and sensations of comfort in using the space.

The purpose of this research is to analyze how architecture students perceive spaces based on two-dimensional sketches, how this perception affects their interpretation and the drawing of such spaces through three-dimensional sketches in immersive virtual reality environments, and how they perceive spaces in IVR environments of both sketched and realistic spaces.

The objectives are:

- To determine the benefits and disadvantages of IVR as a tool for the freehand drawing of architectural spaces and its differences in students of the first and fifth year of architecture studies.

- To determine the advantages and disadvantages of IVR as a tool for the perception of architectural spaces and its differences in students of the first and fifth year of architecture studies. 
- To evaluate the architectural representation (dimensions, scale, proportion, accuracy, and materials) which are drawn freehand in IVR environments by students of the first and fifth year of architecture studies.

Based on these objectives, we established the following research questions:

- Is the use of the IVR an optimal tool for the freehand drawing of architectural spaces by architecture students?

- Is the use of the IVR a useful tool to evaluate the perception of architectural spaces by architecture students?

- Can the three-dimensional models drawn in IVR be used to evaluate the dimensions, scale, proportion, accuracy and materials of the built spaces?

\section{Materials and Methods}

\subsection{The Participants}

The study was carried out by university students of the first and fifth year of the Architecture course of the Universidad Nacional de San Agustín de Arequipa in Peru. In these two courses there was a total of 146 students.

A "student" archetype was defined for the purposes of this study, and only individuals who fit that archetype could participate in the experience. In order to determine if the individuals fit the archetype, they were asked to complete a questionnaire created in Google Forms. People who met the following conditions were sought: interest in freehand drawing, interest in VR video games, a high level of familiarity with computer technologies, and not suffering from vertigo, dizziness, or migraines, among others. In addition, the individuals should not have had experience with the use of HMD, even with video games. In total, 146 students were contacted, of which 48 met the requirements.

Prior to starting the study, a statistical review was performed in order to determine the appropriate sample size needed to guarantee reliable results. Having established the number of archetype students, and considering a statistical confidence level of $95 \%$, a margin of error of 0.1 and a heterogeneity of $50 \%$, it was then possible to establish that the optimal sample size for the research was sixteen participants. Taking into account the availability of the 48 students who fit the archetype, 22 students were randomly chosen to carry out the experience (eleven from the first year and eleven from the fifth year).

The Rey-Osterrieth Complex Figure Test (ROCFT) created by Rey and Osterrieth [40] was applied to the 146 students in order to ascertain the levels of perceptual-motor development, visuospatial capacity, attention, immediate visual memory immediate and the development of graphic activity (Table 1).

Table 1. Participants and averages in the ROCFT test.

\begin{tabular}{|c|c|c|c|c|c|c|}
\hline \multirow[b]{2}{*}{ Participants } & \multicolumn{3}{|c|}{ Population } & \multicolumn{3}{|c|}{ Sample } \\
\hline & $\begin{array}{c}\mathrm{N} \\
\text { (Average Age) }\end{array}$ & $\begin{array}{c}\text { Average } \\
\text { ROCFT1 } \\
\text { (SD) }\end{array}$ & $\begin{array}{c}\text { Average } \\
\text { ROCFT2 } \\
\text { (SD) }\end{array}$ & $\begin{array}{c}n \\
\text { (Average Age) }\end{array}$ & $\begin{array}{c}\text { Average } \\
\text { ROCFT1 } \\
\text { (SD) }\end{array}$ & $\begin{array}{c}\text { Average } \\
\text { ROCFT2 } \\
\text { (SD) }\end{array}$ \\
\hline 1st year & 76 & 34.4 & 27.30 & 11 & 33.6 & 26.3 \\
\hline students & $(18.7)$ & (2.6) & $(4.1)$ & $(18.2)$ & (2.5) & (3.4) \\
\hline 5th year & 70 & 34.1 & 27.2 & 11 & 32.1 & 23.8 \\
\hline students & $(23.0)$ & (5.5) & (6.4) & $(24.1)$ & $(3.2)$ & $(4.8)$ \\
\hline
\end{tabular}

\subsection{The Experimental Design}

The Rey-Osterrieth Complex Figure Test was administered days before the experience of using the HMD to draw in an IVR environment. In this first session, the volunteers were recruited to participate in the experience, and they gave their informed consent to be included in the study, which was conducted in accordance with the Declaration of Helsinki, and the protocol was approved by the Ethics Committee of the Universidad Nacional de 
San Agustin. Furthermore, they gave basic information: age, sex and possible impediments to the use of HMD.

The experimental design had four phases, all of which were carried out on the same day (Figure 1), and for this purpose questionnaires, grading sheets and different graphic materials were created:

- Phase 1: Two hand drawing sketches and Questionnaire 1 to evaluate the perception of the visualized space based on 2D sketches. This questionnaire had five questions: the first to ascertain the perception of the domain of the space that goes from totally private to totally public (Likert of 5 levels); the second to ascertain the use of the space with the alternatives to watch, play, read, rest and contemplate; the third open question to give the measurements of the length, width and height of the space; the fourth open question to write four materials; and the last question to ascertain the perceived sensations, which were categorized into 5 levels, each with three alternatives, as shown in Questionary 1 (see Appendix A).

- Phase 2: A grading sheet to evaluate the accuracy of the three-dimensional drawing in the IVR. The grading sheet considered five indicators: measures, scale, proportion, accuracy and materials, in order to determine the degree of precision achieved when it was drawn in three dimensions. The detail of the calculations is shown in the results of the second phase (Tables 3-7).

- $\quad$ Phase 3: Questionnaire 2, to ascertain the opinion and perception of drawing in 3D in an IVR environment. This questionnaire had 18 questions, the first ten (Likert of 5 levels) investigated the usefulness of using the tool in different aspects and moments of drawing and design, and determined the aspects that offered the most realism to the virtual experience. The next two questions were open and sought to ascertain the advantages and disadvantages that students found when using the tool to draw and to perceive the spaces. Finally, the last six questions (5-level Likert) found the similarities between the use of the IVR and the perception of spaces based on sketches with the real perception of spaces and the action of drawing in two dimensions, and the comfort, ease and precision of drawing using the tool in IVR.

- Phase 4: A three-dimensional model of the space, and Questionnaire 3 to evaluate the perception of the 3D space visualized with HMD and comparisons with previous perceptions. This questionnaire had ten questions, the first six with 5 levels on the Likert scale investigated the factors that gave the experience more realism. The seventh asked about the most relevant characteristics that gave realism to the space. The eighth and ninth questions sought to ascertain the similarity of the perception of this space with respect to the space drawn in 3D and with the one observed in the sketches. The tenth question was exactly the same as that applied in phase 1, which sought to ascertain the perceived sensations categorized into 5 levels, each with three alternatives, as shown in Questionary 3 (see Appendix A).

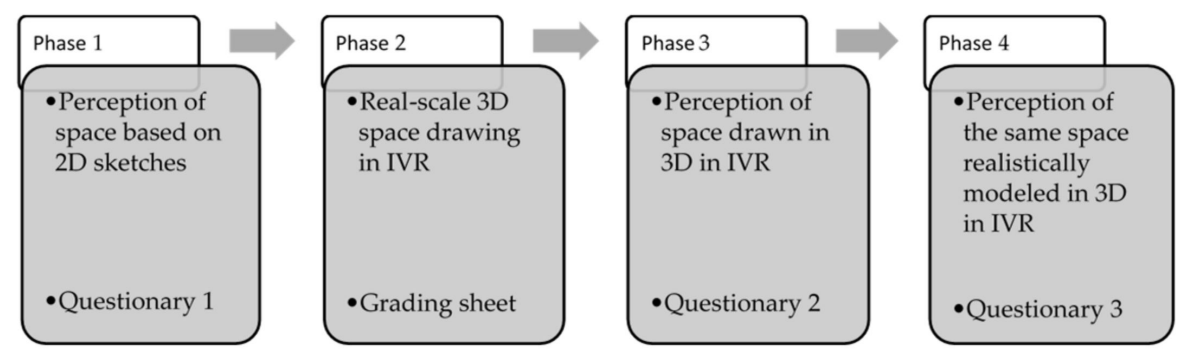

Figure 1. The four phases of the experimental study (the questionaries are available in Appendix A). 


\subsubsection{First Phase: The Perception of Space Based on 2D Sketches}

In this phase, the participants were presented with a color sketched drawing of an architectural space (Figure 2) that they observed and studied for five minutes. Then, Questionnaire 1 was prescribed to them to complete in order to ascertain their perception of the space observed. The questions inquired about their perception of the degree of domain (public/private), of the use that can be given to the space, of the three dimensions (width, length, and height) and of the construction materials used. They were then asked about the sensation they would feel when imagining themselves within the space observed in the sketch. For each of the spaces, they were given five categories to choose one of the three alternatives in each one of them. For the scale and size category, the alternatives provided were restlessness, balance or grandeur. In the used material category, the alternatives were warmth/comfort, fragility/exposure, or distance/frigidity; for the category of the architectural style, the options were elegance/satisfaction, simplicity/serenity or eccentricism/surprise; for the use and related activity category the options were joy/theatricality, sadness/nostalgia, or emotion/spirituality. Finally, for the category of the enclosure degree, the options were protection, calmness or freedom.
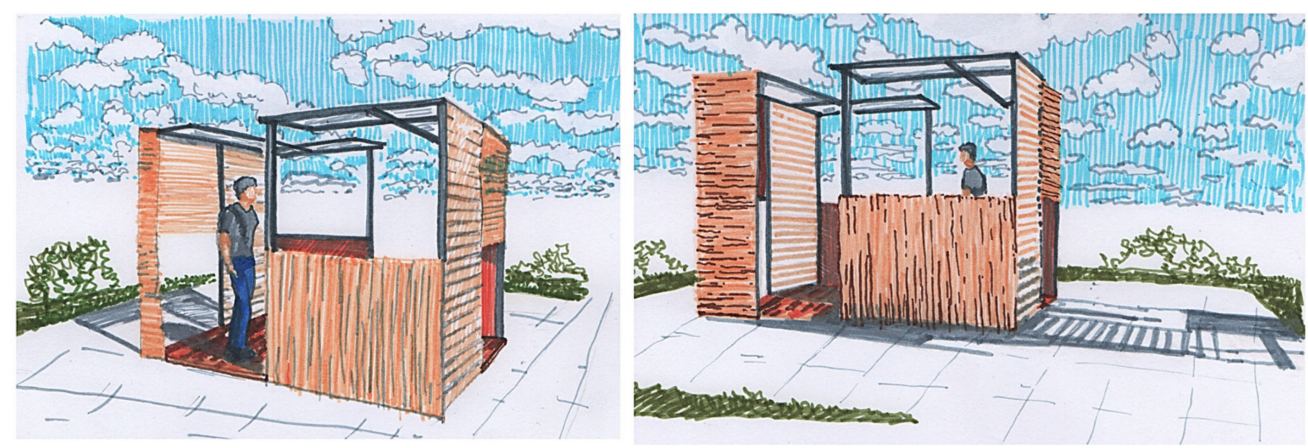

Figure 2. Freehand sketches of the space.

In order to compare the perceived sensations, the opinions of five experts were requested. They were the teachers of the "Architectural Design Workshop" class from the first year, and the two designers of the space (the co-investigators of this research) who established the predominant sensations shown.

\subsubsection{Second Phase: The Real-Scale 3D Drawing of the Space in IVR}

In the second phase, each participant was provided with a Head-Mounted Display Oculus Rift. For fifteen minutes, the participants were briefly trained in the basic tools of the Tilt Brush software, and this period also served to allow them to adapt to the virtual environment. After a short break of $1 \mathrm{~min}$, the participants were asked about the existence of any discomfort linked to the presence of cybersickness. After these minutes of training and a break, each participant was given 45 min and asked to construct a full-scale replica of the three-dimensional sketch of the building that was analyzed in phase 1. For this activity, only the brushes for freehand drawing (no straight lines), the color palette and the scale tool were used (Figure 3). Previously, the two images of space that they had seen in paper format had been imported into the virtual environment in order to retain them permanently as a reference. At the end of the activity, the 3D drawings were evaluated with a grading sheet to ascertain the dimensions, scale, proportion, accuracy and representation of the materials. 


\subsubsection{Third Phase: The Perception of Space Drawn in 3D in IVR}

After each participant drew and built the space in IVR, they were asked to use the HMD to access it, observe it and walk through it for five minutes in order to recognize, experience and perceive it, and then to record their perceptions and impressions in Questionnaire 2, providing their opinion regarding the usefulness of the tool, the realism of the environment, the advantages and disadvantages of using the IVR, and the similarities with other aspects.
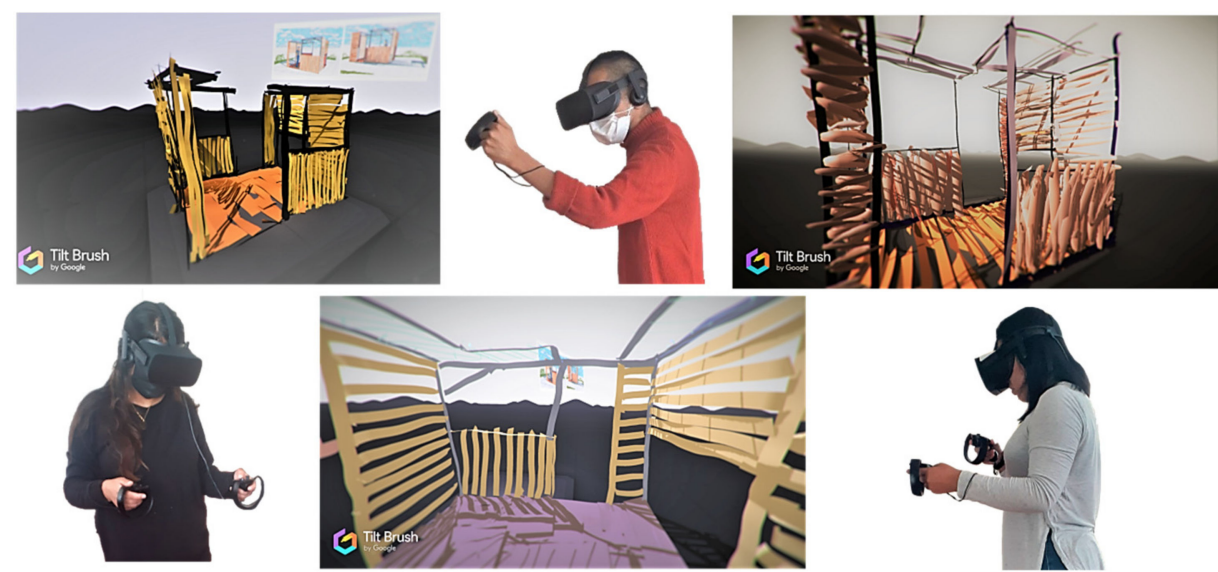

Figure 3. Real-scale 3D space drawing in IVR.

2.2.4. Fourth Phase: The Perception of the Same Space Realistically Modeled in 3D in IVR

Finally, each participant again used the HMDs to enter a virtual environment in which they found the same space, but this time modeled realistically, on a real scale, with materials, daylight, shadows, and the outdoor environment (Figure 4). For five minutes, each participant was able to enter the space, walk through it, exit it and explore it. In order to measure the perceptions of the space, Questionnaire 3 was used, which asked for the appreciation regarding the perceived realism in the virtual environment, the comparisons with the previous perceptions of the same space, and the sensations perceived in the space to be compared with the responses to the first questionnaire.

The questionnaires in general, except for the open questions, had five levels on the Likert scale.
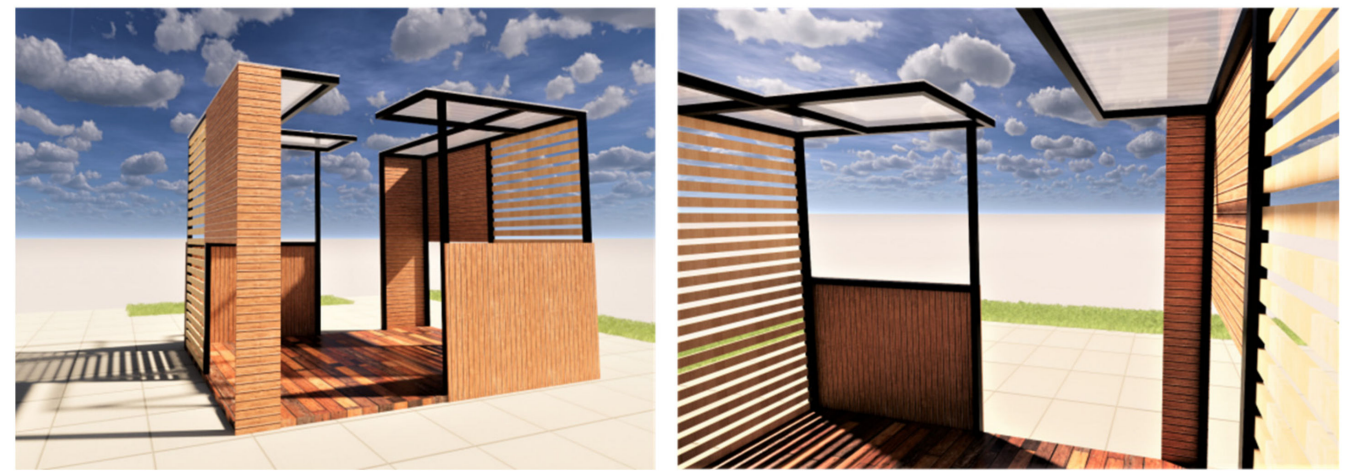

Figure 4. Realistic model of the architectural space. 


\subsection{Materials and Equipment}

For the first phase, two freehand sketches drawn from a conical perspective at the pedestrian level of a small space were used (see Figure 2); such two-dimensional drawings in paper format were delivered to the participants printed in A4 format and in color. The architectural space represented was of intermediate complexity and small in size due to the need to be drawn three-dimensionally in IVR.

For the following phases, a desktop workstation was wired to the virtual reality system so that the three-dimensional drawings could be recorded. The TiltBrush application, a commercial application developed by Google, additional hardware for the drawing space and the gathering of the participants perceptions and results, and components of a PC with 8GB RAM, connected to an Oculus Rift VR headset, and the software SketchUp Pro 2019, in addition to VR Enscape 3D version 2.6 were all used throughout the study.

\subsection{Methodology Limitations}

When the archetype was defined, it is useful to ask appropriate questions to select participants. Although it was not indicated in the questions on the form, it was necessary to confirm that none of the participants were affected by colour blindness. It is convenient that all of the participants were free of this condition because they had to indicate their perception of the spaces, and two of the variables that influence this are the colours and types of materials used. On the other hand, although the sessions were conducted individually and each participant was supervised, and the researchers informed the participants of the need to terminate the session if at any time they experienced discomfort, vertigo or dizziness, it is advisable to administer the Simulator Sickness Questionnaire (SSQ) [41] to the participant at the end of the experimental session with the HMD.

Although the use of VR technology has many advantages, the effects on the health and safety of users is important and is an area that is worth exploring and considering. The main concern relates to the temporary effects induced by VR; these effects have been referred to as "cybersickness". This condition is not a disease, but a physiological response to the unusual stimulus observed and studied in the field of flight simulation [42].

Cyberdizziness includes different symptoms, such as malaise, dizziness, nausea, eyestrain, headaches, epigastric pain, cold sweats, flushing, increased salivation, belching, drowsiness, and vomiting, among others [41,43]. Few instruments exist to measure VRinduced side effects; the most widely used is the Simulator Sickness Questionnaire [41]. This questionnaire was designed to be administered in different devices that use simulation, including VR, and where different display devices (HMD or CAVE systems) are used. The questionnaire consists of 16 items, which are grouped into three subscales or factors: (a) oculomotor symptoms (e.g., visual fatigue, lack of concentration, etc.), (b) disorientation (e.g., dizziness and lightheadedness), and (c) nausea (including belching, increased salivation, etc.). Each item is assessed on a four-point scale ( $0=$ "feel nothing", 1 = "a little", 2 = "medium" and, 3 = "a lot"). The total score of the SSQ is the sum of the scores of the three subscales. This factor structure has been widely used to measure the frequency of cyberdizziness in the general population [43,44]. A brief explanation of the Simulator Sickness Questionnaire (SSQ) can be found in the work of the University of Minnesota Affordance Perception-Action Lab [45].

The SSQ questionnaire is a useful tool for conducting specific research, or as a supplement to specific research studies. Through the SSQ, it is possible to assess the impact of cyberdizziness on the user population of VR technologies and the feasibility of using IVR experiences. In general, it allows us to analyze whether the user is affected by any symptoms of dizziness or discomfort after the use of the VR device and technology.

Figure 5 defines a methodological approach for user-testing in VR environments. 


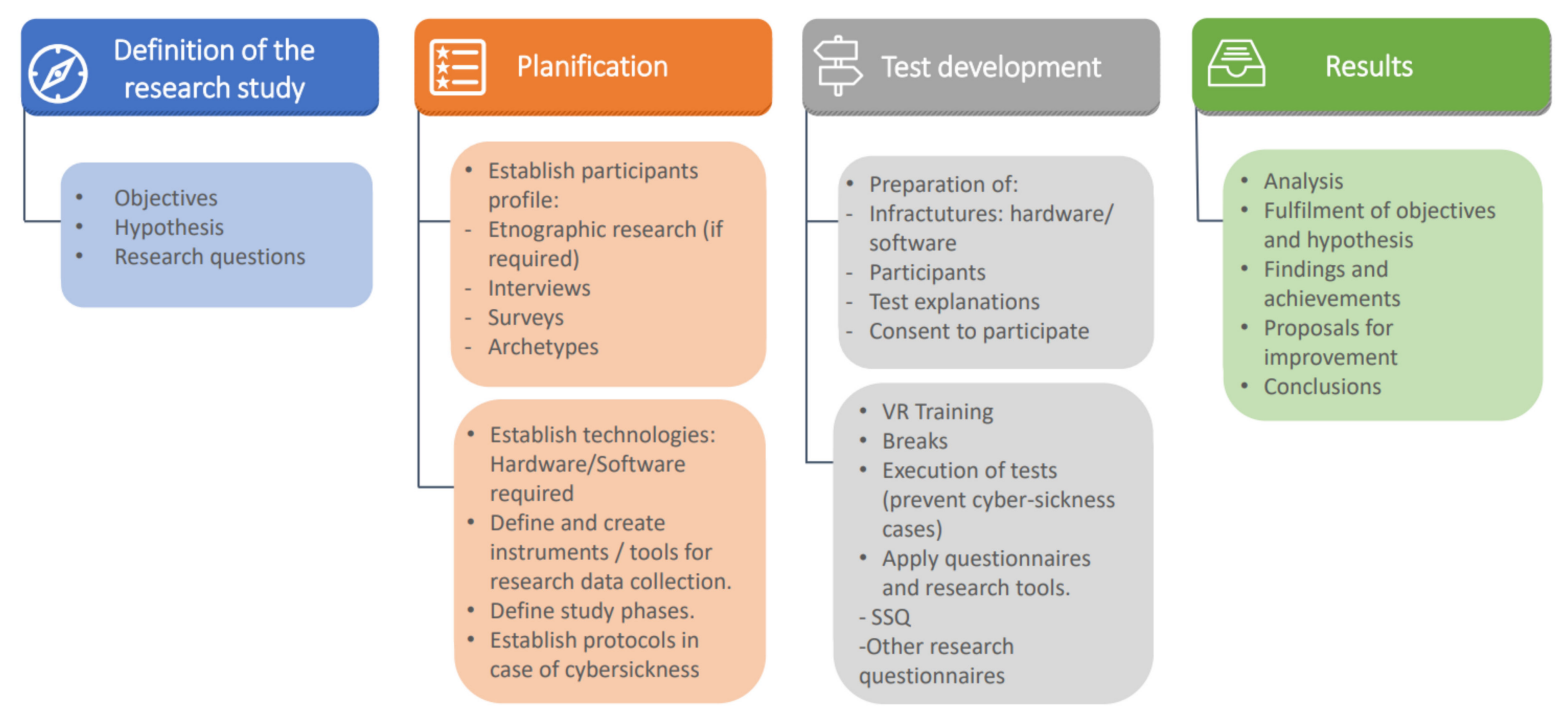

Figure 5. VR research design proposal.

\section{Results}

\subsection{First Phase}

In order to ascertain the global perception of the architectural space, the perception of the five aspects shown in Table 2 was quantified. Regarding the public or private domain of the space, on a 5-level Likert scale, five points or 100\% were assigned to "totally public" (which is the real domain) and a point to "totally private"; it turned out that the perception of the domain of space is not so high, and was more accurate from the fifth-year students. In order to ascertain the perception of the probable use of the space, five points or 100\% were assigned to those who chose the use of contemplation (which is the real use), four points to use for play, three points to use for rest, two for reading and a point for watching; as a result, the perception of the use of the space only based on 2D sketches was not very high. The real measurements of the space were in width $2.40 \mathrm{~m}$, in length $3.30 \mathrm{~m}$ and in height $2.40 \mathrm{~m}$; five points were awarded to the participant who got the three measurements right, and the score was lowered as the error margin increased and got farther away from the real measurements; in this way, a high perception and estimation of the measures was observed (more than $83 \%$ ). In order to evaluate the perception of the construction materials, an open question was asked where those who mentioned the three materials: wood, metal and polycarbonate obtained five points, or $100 \%$; those who got only two materials right received $67 \%$; those who got one right received $33 \%$, and those who did not get it right received $0 \%$. This resulted in a high percentage $(87.9 \%)$ for fifth-year students and a lower percentage for first-year students. There is no statistically significant difference in the perception of the five aspects studied because, applying the T-student test, all of the $p$-values were greater than 0.05 .

Table 2. Perception by participants of the five aspects of space based on the 2D sketches.

\begin{tabular}{ccccccc}
\hline Groups & Domain & Use & Measurements & Materials & Sensations & Total \\
\hline First year & $61.8 \%$ & $57.6 \%$ & $83.6 \%$ & $78.7 \%$ & $65.8 \%$ & $69.5 \%$ \\
Fifth & $69.1 \%$ & $57.9 \%$ & $83.4 \%$ & $87.9 \%$ & $62.4 \%$ & $72.1 \%$ \\
$\begin{array}{c}\text { year } \\
p \text {-value }\end{array}$ & 0.132 & 0.821 & 0.788 & 0.114 & 0.096 & - \\
\hline
\end{tabular}

The perception of the sensations deserves a more detailed explanation, which is given below; however, we can anticipate, based on Table 2, that the global perception of space is quite high and acceptable to be a perception only based on the two two-dimensional drawings shown in Figure 2. 
Regarding the sensations, a clear trend was found for the material and use/activity categories, in which the sensations of the fifth-year students were closer to those of the experts, as opposed to the first-years, who were further apart as show Figure 6. This trend was reversed for the other three categories, in which the sensations of the first-year students were closer to those of the experts, and the fifth-year students choose three sensations, restlessness $(18.2 \%)$, elegance/satisfaction $(9.1 \%)$ and protection $(45.5 \%)$, which very far from those proposed by the experts. It can be appreciated, however, that even experts have small variations when perceiving the sensations that a space can evoke. Finally, it should be noted that it was only the two designers who, in addition to creating the space, experienced it in IVR, while the five teachers perceived it based on the 2D sketches and an interactive three-dimensional model.

\section{Sensations perceived by students of the space sketched in 2D compared with expert opinion}

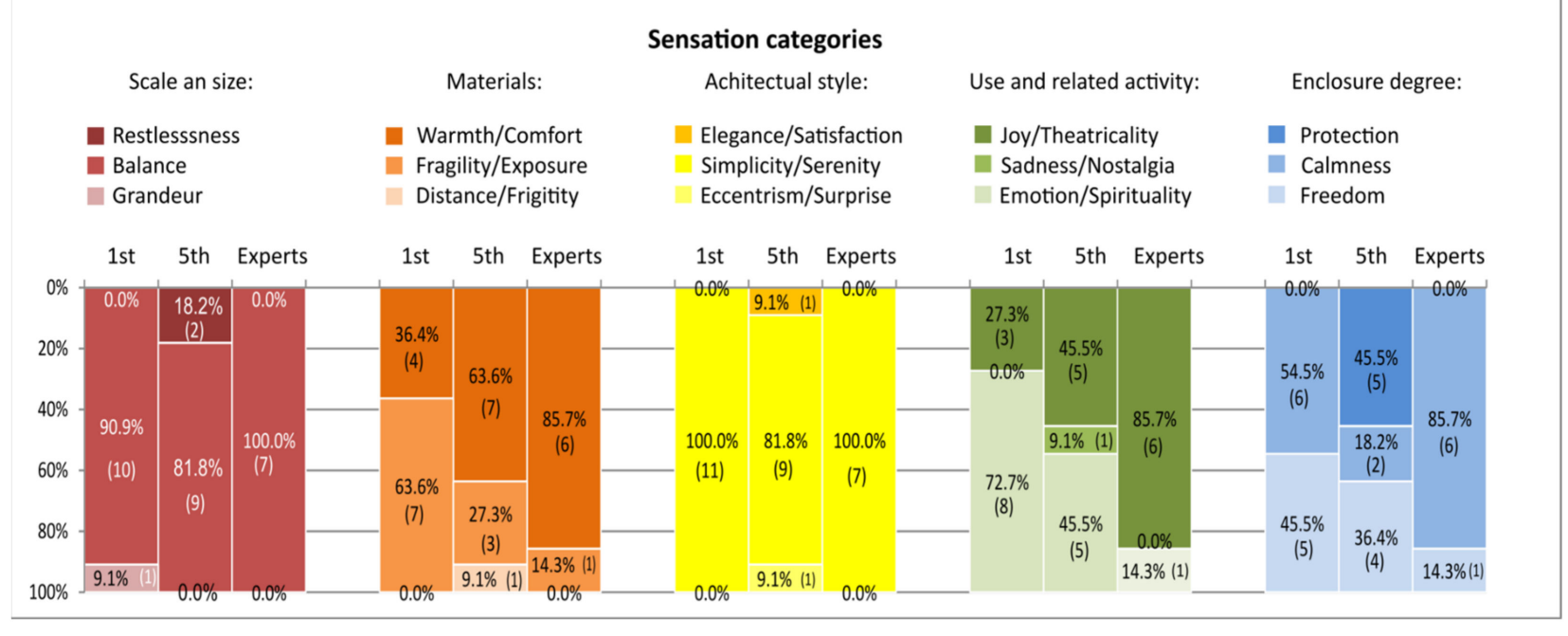

Figure 6. Sensations perceived by the students based on the 2D sketch compared to the opinions of the experts.

\subsection{Second Phase}

For the second phase, a grading sheet was created to determine the precision of the 3D drawing created in the IVR; for this, the following indicators were established: measurements, scale, proportion, accuracy, and materials.

The real measurements of the space were $2.40 \mathrm{~m}$ in width, $3.30 \mathrm{~m}$ in length and $2.40 \mathrm{~m}$ in height; five points were awarded to the participant who got the three measurements right, and the score was lowered as it got further away from the real measurements. Table 3 shows that the estimation of the measures expressed from the 2D sketches were more accurate than those finally drawn and built in IVR, with the first-year students being the ones who deviated the most from the real measurements.

Table 3. Average scores in the estimation and 3D drawing of the three measurements of space.

\begin{tabular}{ccc}
\hline Student Groups & Measurements Found in the 3D Model Built in IVR \\
\hline & Average score & Percentage \\
First year & 3.74 & $74.8 \%$ \\
Fifth year & 4.03 & $80.6 \%$ \\
\hline
\end{tabular}

In order to evaluate the scale of the drawing made in the IVR as a percentage, the proportion of the three measurements (width, length, and height) between the corresponding real measurement and then the average of those results was calculated, ideally obtaining $100 \%$ if the size was like the real one (scale 1:1) and values greater or less than $100 \%$ when 
the drawing was made larger or smaller, respectively. Table 4 shows that all of the students drew the space in IVR with a scale very close to the natural scale.

Table 4. Average scale of the space drawn in 3D.

\begin{tabular}{ccc}
\hline Student Groups & Average Scale & Scale Approximation in $\%$ \\
\hline First year & $1.0772: 1$ & $92.90 \%$ \\
Fifth year & $1.0713:$ & $93.40 \%$ \\
\hline
\end{tabular}

In order to evaluate the proportion, the quotient between the measurements of the space drawn in IVR (width, length, and height) and the corresponding real measurement was calculated. In order to verify that these values were equal to or close to the average, the standard deviation $(\sigma)$ of these three results was used, with zero meaning that the measurements were proportional to the real ones, and with higher values meaning that there was a greater degree of error. Considering that it can vary as much as its value ( $100 \%$ variation), the coefficient of variation with respect to the average was also calculated. As such, this coefficient represents the percentage of variation. Table 5 shows that the percentages of variation were low, which represents good proportions in the drawing.

Table 5. Proportion of the space drawn in 3D.

\begin{tabular}{|c|c|c|c|c|c|}
\hline & Width & Length & Height & $\begin{array}{c}\text { Standard } \\
\text { Deviation }(\sigma)\end{array}$ & $\begin{array}{l}\text { Coefficient of } \\
\text { Variation (\%) }\end{array}$ \\
\hline $\begin{array}{l}\text { Averages of } \\
\text { measurements given by } \\
\text { first-year participants }\end{array}$ & 2.61 & 3.34 & 2.72 & & \\
\hline Real measurements & 2.40 & 3.30 & 2.40 & & \\
\hline $\begin{array}{l}\text { Proportion (must be equal) } \\
\text { Measure/Real Measure }\end{array}$ & 1.09 & 1.01 & 1.13 & 0.0619 & 17.39 \\
\hline $\begin{array}{l}\text { Averages of } \\
\text { measurements given by } \\
\text { fifth-year participants }\end{array}$ & 2.62 & 3.28 & 2.71 & & \\
\hline Real measurements & 2.40 & 3.30 & 2.40 & & \\
\hline $\begin{array}{l}\text { Proportion (must be equal) } \\
\text { Measure/Real Measure }\end{array}$ & 1.09 & 0.99 & 1.13 & 0.0702 & 15.27 \\
\hline
\end{tabular}

The evaluation of the accuracy in the drawing of the space in the IVR was carried out by evaluating each of the four faces of the space in addition to the floor and ceiling. During the evaluation each face was rated, assigning a point if it was drawn correctly, half a point if it was deformed or incomplete but recognizable, and zero points if it was unrecognizable or absent. The perfect and exact drawing would score six points. The results shown in Table 6 show that the accuracy of the 3D drawing in the IVR was very close to the real one.

Table 6. Accuracy in the average score and percentage of the space drawn in 3D.

\begin{tabular}{ccc}
\hline Student Groups & Accuracy in Points (Score) & Accuracy in Percentage \\
\hline First year & 5.18 & $86.4 \%$ \\
Fifth year & 5.14 & $85.6 \%$ \\
\hline
\end{tabular}

Finally, in order to evaluate the representation of the materials (Table 7), the considerations were the use of the handmade lines, that the color and opacity were represented for the polycarbonate of the ceiling, for the two wooden presentations on the walls, for the metal of the structure and for the wood of the floor; in this way, the representation closest to reality obtained 5 points $(100 \%)$. 
Table 7. Representation of the materials in the average score and the percentage of the space drawn in $3 \mathrm{D}$.

\begin{tabular}{ccc}
\hline Student Groups & Materials in Points (Score) & Materials in Percentage \\
\hline First year & 4.18 & $83.6 \%$ \\
Fifth year & 3.73 & $74.5 \%$ \\
\hline
\end{tabular}

The global results based on the five indicators show that the precision of the 3D drawing created in the IVR was high, and that there was little variation between the students of the first and fifth years. In order to compare the precision of the 3D drawing created in the IVR between both groups, a T-student test was applied for each of the evaluated components; it was found that there was only a statistically significant difference in the "material" component ( $p$-value $<0.05$ ). Table 8 show these statistical results.

Table 8. Global precision of the space drawn in 3D.

\begin{tabular}{ccccccc}
\hline $\begin{array}{c}\text { Student } \\
\text { Groups }\end{array}$ & Measurements & Scale & Proportion & Accuracy & Materials & Total \\
\hline First year & $74.80 \%$ & $92.90 \%$ & $82.61 \%$ & $86.40 \%$ & $83.60 \%$ & $84.06 \%$ \\
Fifth year & $80.60 \%$ & $93.40 \%$ & $84.73 \%$ & $85.60 \%$ & $74.50 \%$ & $83.77 \%$ \\
$p$-value & 0.159 & 0.788 & 0.732 & 0.654 & 0.012 & - \\
\hline
\end{tabular}

\subsection{Third Phase}

For the third phase, based on the Questionnaire 2, the students' viewpoints regarding five aspects of the experience of using the IVR were found: the usefulness for their professional development, the realism of the IVR, the advantages and disadvantages, the similarities, and other aspects of use of the tool.

The utility of the IVR for drawing and exploring architectural spaces was highly valued by all of the students, while the usefulness of capturing the initial design ideas or developing designs was less valued by fifth-year students. Regarding the realism they felt in the virtual environment, all of the students agree that this quality was due to immersion, to the real scale of what was built and to the possibility of seeing in all directions at will. They give less value to the shadows (which were faint), to the materials (which were not realistic due to the tool) and to the environment (somewhat gray and darkened), all of which were less helpful to experience the environment as reality (see Figure 7). These last results largely overlap with the results obtained in the fourth phase.

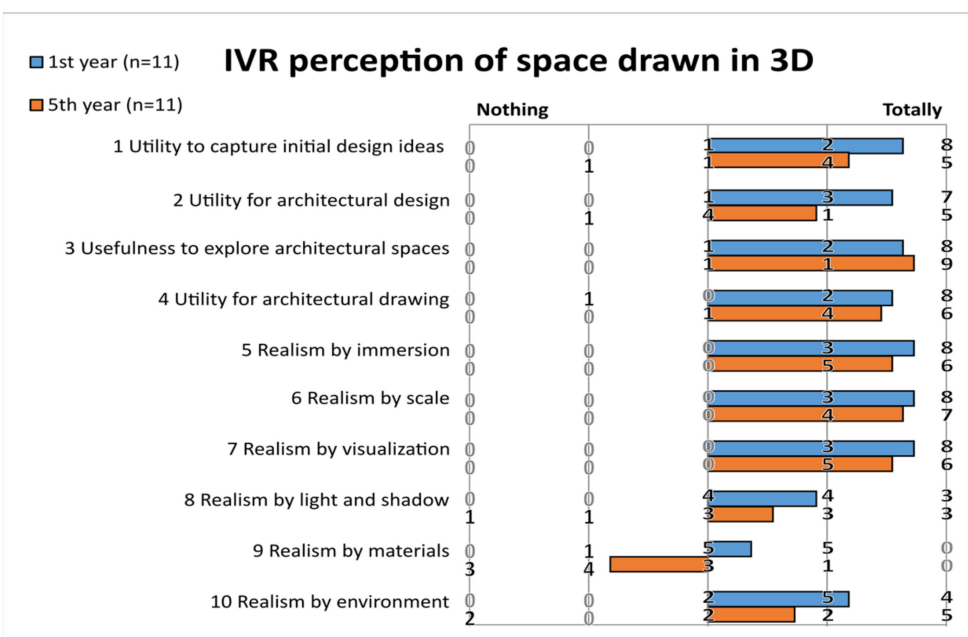

Figure 7. IVR perception of the space drawn in 3D. 
The advantages of the IVR most valued by students were the immersion of the virtual environment, the natural or real scale in which the drawn space could be experienced, and the possibility of expressing ideas quickly in the drawing and design process (Figure 8a). On the other hand, the biggest disadvantages for the students were the low precision shown by the drawing tool, the low or lack of realism of the materials, and the discomfort of having a helmet mounted on the head for a long time (Figure 8b).

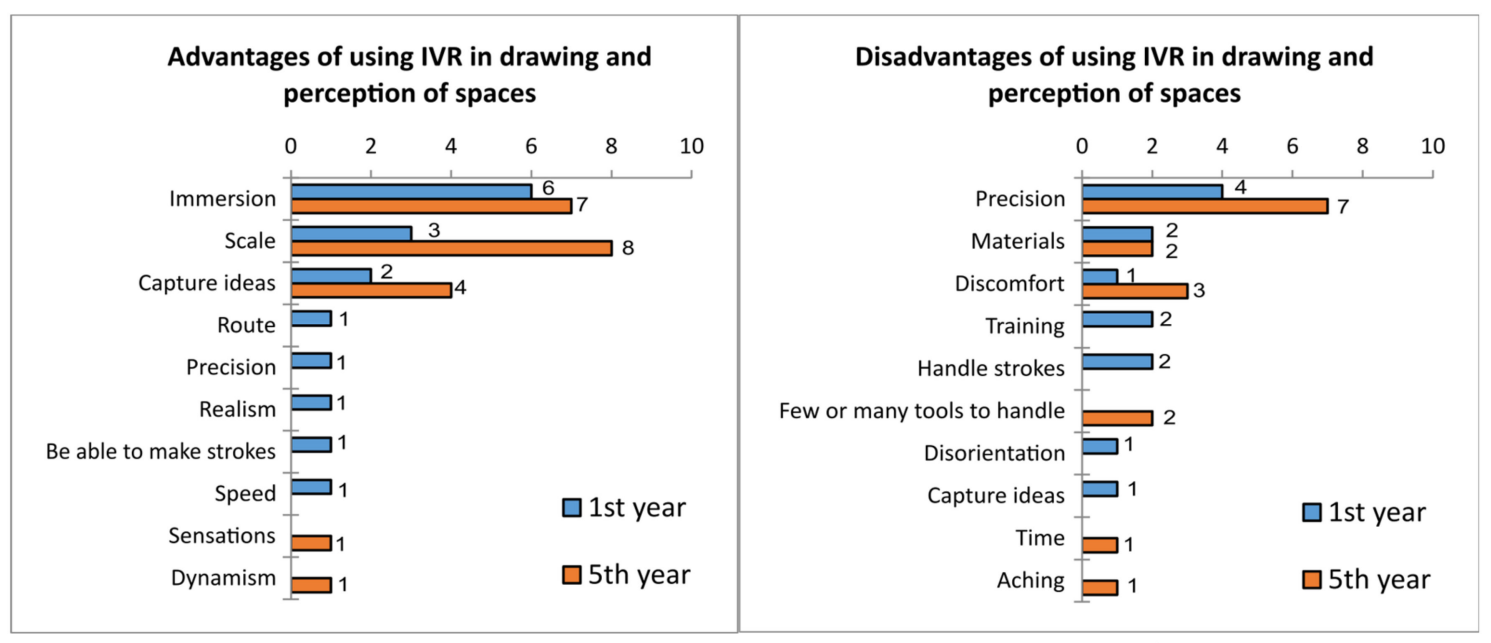

(a)

(b)

Figure 8. Advantages (a) and disadvantages (b) of the use of IVR in the drawing and perception of spaces.

Finally, the students considered that the perceptions which were achieved in the virtual reality environment were not entirely similar to the perceptions based on two-dimensional drawings, and that these virtual perceptions were more similar to those achieved in the real world. Regarding the action of drawing in 3D in the IVR compared to the action of drawing by hand in 2D, the first-year students found fewer similarities. The convenience of using freehand strokes was better valued than the ease of completing the drawing, and much greater precision was achieved precisely because they were only freehand strokes (Figure 9).

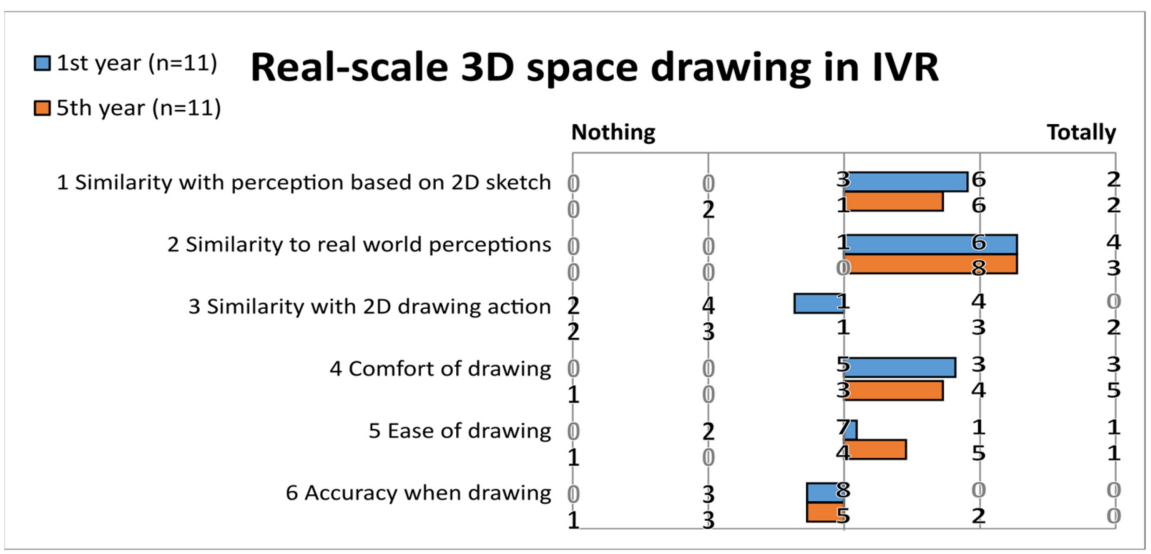

Figure 9. Real-scale 3D space drawing in the IVR.

\subsection{Fourth Phase}

Questionnaire 3 evaluates the perception of the 3D space by visualizing the threedimensional models of architectural space with HMD. The reliability of this questionnaire was calculated using Cronbach's alpha to determine whether it takes stable measurements, obtaining a result of 0.874 , which indicates that the questionnaire was reliable. 
After experiencing the same space in IVR, but this time modeled in a realistic way, the students almost unanimously considered that immersion was the most relevant characteristic when perceiving an architectural space. This characteristic, together with the scale and the possibility of looking in all directions at will was highly valued by the participants. Although the lights and shadows in this phase were more realistic, in the same way as the construction materials and the external environment, the students did not value as much these characteristics of the model experienced in the IVR (Figure 10).

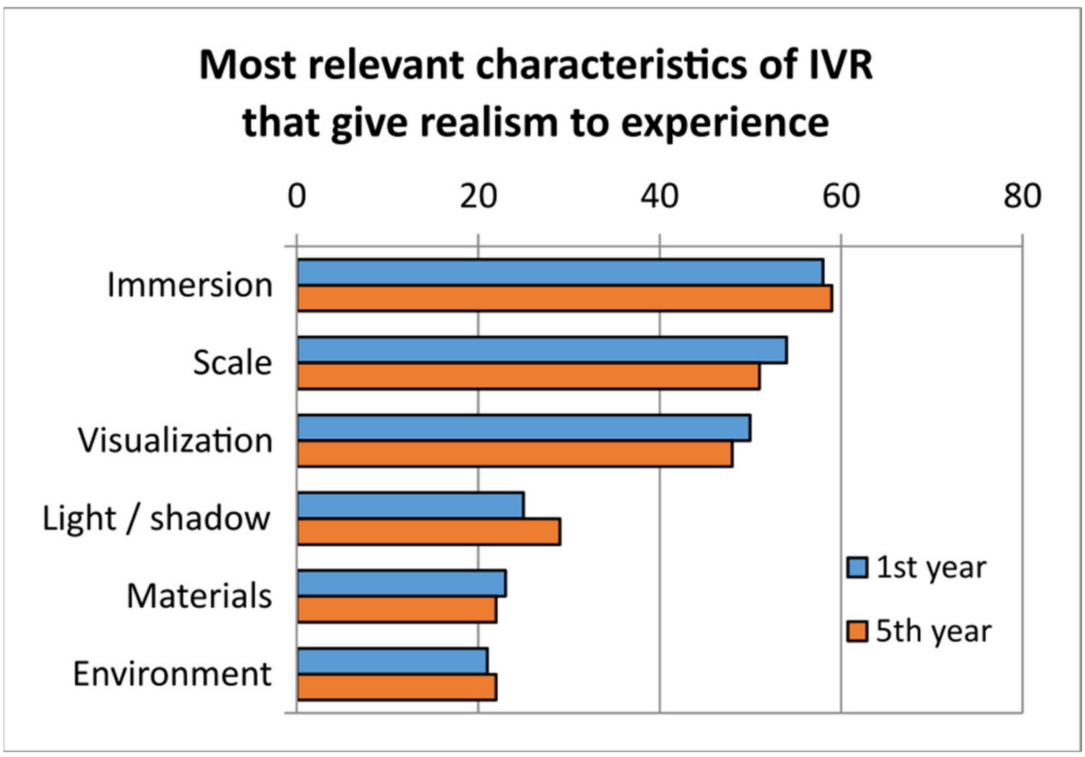

Figure 10. Most relevant characteristics of IVR that give realism to the experience.

In general, the sensations perceived from the same space, but this time experienced in an IVR environment, were closer to those expressed by the experts (Figure 11). However, there were three sensations that strayed further than expected: grandeur (of scale/size), elegance/satisfaction (of architectural style), and freedom (of the degree of enclosure).

\section{Sensations perceived by students of the photorealistic space in IVR compared with expert opinion}

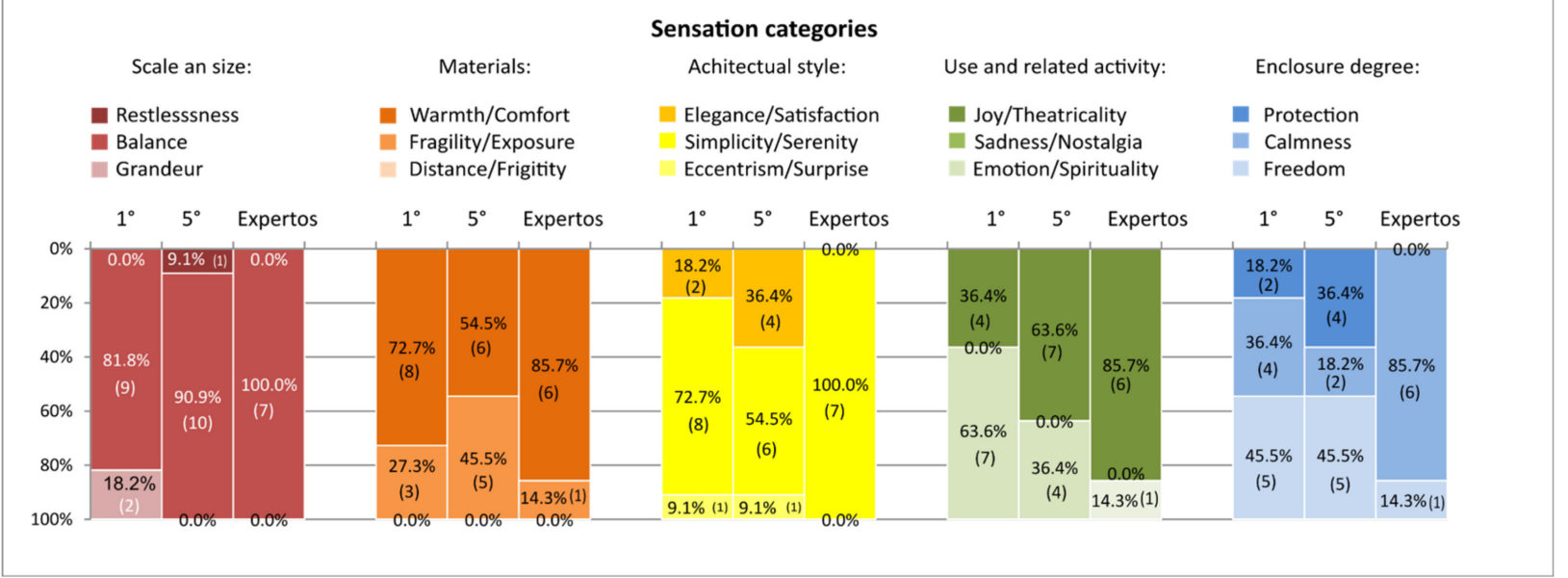

Figure 11. Sensations perceived by the students of the photorealistic space in the IVR compared with the expert opinions.

Table 9 shows the variation that the sensations had in the perception of space based on 2D sketches and based on experimentation with IVR. The sensation that had the most variation was related to the degree of closure; both groups changed their initial percep- 
tion of peace/protection for freedom, although the last one was not supported by the experts. The other sensation that had the most variation was related to the materials, and it was the first-year students who went from the sensation of fragility/exposure to warmth/comfort. Finally, the fifth-year students changed their feelings related to the use and activity from emotion/spirituality to joy/theatricality, emotions which were not supported by the experts.

Table 9. Analysis of the variation in the predominant sensations.

\begin{tabular}{|c|c|c|c|c|}
\hline Category & Student Groups & $\begin{array}{l}\text { Initial Predominant } \\
\text { Sensation after Perception } \\
\text { with 2D Sketches }\end{array}$ & $\begin{array}{l}\text { Final Predominant } \\
\text { Sensation after } \\
\text { Perception with IVR }\end{array}$ & Variation \\
\hline \multirow{2}{*}{ Scale and size } & $1 \mathrm{st}$ & Balance $90.9 \%$ & Balance $81.8 \%$ & $-9.1 \%$ \\
\hline & 5 th & Balance $81.8 \%$ & Balance $90.9 \%$ & $+9.1 \%$ \\
\hline \multirow[t]{2}{*}{ Materials } & 1 st & Fragility/exposure $63.6 \%$ & $\begin{array}{c}\text { Fragility/exposure } 27.3 \% \\
\text { Switched to } \\
\text { warmth/comfort } 72.7 \%\end{array}$ & $-36.3 \%$ \\
\hline & 5 th & Warmth/comfort 63.6\% & Warmth/comfort 54.5\% & $-9.1 \%$ \\
\hline \multirow{2}{*}{$\begin{array}{l}\text { Architectonic } \\
\text { style }\end{array}$} & 1 st & Simplicity/serenity $100.0 \%$ & Simplicity/serenity72.7\% & $-27.3 \%$ \\
\hline & 5 th & Simplicity/serenity $81.8 \%$ & Simplicity/serenity $54.5 \%$ & $-27.3 \%$ \\
\hline \multirow[t]{2}{*}{ Use and activity } & $1 \mathrm{st}$ & Emotion/spirituality $72.7 \%$ & $\begin{array}{l}\text { Emotion/spirituality } 63.6 \% \\
\text { Emotion/spirituality } 36.4 \%\end{array}$ & $-9.1 \%$ \\
\hline & 5 th & Emotion/spirituality $45.5 \%$ & $\begin{array}{c}\text { Switched to } \\
\text { Joy/theatricality } 63.6 \%\end{array}$ & $-9.1 \%$ \\
\hline \multirow{2}{*}{$\begin{array}{l}\text { Degree of } \\
\text { closure }\end{array}$} & 1 st & Calmness $54.5 \%$ & $\begin{array}{c}\text { Calmness 36.4\% } \\
\text { Switched to freedom } 45.5 \%\end{array}$ & $18.0 \%$ \\
\hline & 5 th & Protection $45.5 \%$ & $\begin{array}{c}\text { Protection } 36.4 \% \\
\text { Switched to freedom } 45.5 \%\end{array}$ & $-9.1 \%$ \\
\hline
\end{tabular}

Finally, the students considered that the perceptions of the space created realistically and experienced in the IVR were more similar to the perceptions they had of the same space when they appreciated it based on 2D sketches than those of the space drawn and built by themselves (Figure 12).

\begin{tabular}{|l|l|}
\hline & Perception of the same space \\
$\square$ 1st year & realistically modeled in 3D in IVR \\
$\square 5$ th year & \\
\hline $\begin{array}{c}\text { Similarity with perception based on 3D } \\
\text { sketches drawn by themselves }\end{array}$ & \\
\hline
\end{tabular}

Figure 12. Perception of the same space realistically modeled in $3 \mathrm{D}$ in the IVR.

\section{Discussion}

The importance of sketches as a physical product for the perception of spaces is confirmed by considering the five indicators (domain, use, measurements, materials and sensations) that allow us to ascertain the degree of perception of a space; the students achieved, in global terms, $70 \%$ of the total perception of the space. This finding confirms what was expressed by Gomes et al. [10], that the drawing stimulates the reader to live the observed space, but does not confirm the second part of the statement that says that the drawing actually stimulates the reader to relive the space, because that reading is influenced by the body memory of their experiences, as well as their culture and other factors. In the research, the experience of five years of study compared with the limited 
experience of the freshman should have made a greater difference in favor of the fifth-year students, but it did not. An explanation can be found in the fact that first-year students are full of experimentation and the development of the perception of spaces and the sensations that they can provoke, while those of the fifth year are more committed to solving larger architectural problems, problems of the city and planning, and technical-normative aspects that could distract them from the sensations produced by smaller-scale spaces. In addition, when asking about the participant's sensations, we are relying on their emotional awareness and their ability to describe the sensations they perceive with exact adjectives, a faculty which may not be very well established in each student, which leads us to consider the need to combine questionnaires with other forms of measurement such as biosensors that give quantitative reading of the body's response in order to determine emotion in real time, as some researchers have recommended [26].

Regarding the drawing made in 3D and using the IVR, although the experimentation was oriented towards a freehand schematic drawing, a representation of the architectural space was achieved with high precision in its five indicators (measurements, scale, proportion, accuracy, and materials), indicating that drawing using haptic controls is suitable for full-scale freehand drawing. A similar experience [32] determined that the VR sketch helps to improve mental processing for the transformation and reconstruction of ideas and also facilitates the understanding of spatial relationships, which has surely allowed the participants in this study to achieve more precise drawings.

At this point it should be clarified that the IVR drawing, in addition to using the hands to perform the strokes, uses the whole body, and even more so when the drawing is a realscale architectural space that the draftsman can enter. This condition means that the IVR drawing can recover the physical and psychological relationship that is created between the subject and the space during the spatial experience, removing the need to depend completely on the sense of sight [16] and allowing reliance on other senses, such as the haptic. Nevertheless, this important condition makes greater demands on the perception, motor and spatial skills of the users [46]. The influence of motor skills on the performance of spatial skills tasks was demonstrated in the meta-analysis by Voyer and Jansen [47], and should be studied in the future in order to determine which motor and spatial skills directly affect architectural design and drawing in IVR. Important evidence was gathered in a previous study [48] which concluded that spatial skills (including mental rotation and spatial orientation) can be trained with the drawing of architectural spaces at full scale in IVR. Such training required not only spatial cognitive processes but also motor skills because the drawings were larger than the draftsman.

The apparent utility that first-year students confer to IVR technology in terms of capturing the initial ideas of the design and in the architectural design itself is due to the fact that the scale of the space selected for the experiment was the one that is handled in the first year, while the design scale in the last year is urban. Both groups recognize the high utility of IVR for drawing and for exploring architectural spaces, while on the other hand, the realism found in the virtual environment at the time of drawing is high, but the natural lighting, the external environment and the construction materials were the least valued factors to achieve such realism; this is because the application used for the experimentation (Tilt Brush) is focused on creating objects in three dimensions, rather than on the realistic presentation of the object. These same characteristics, when the student experienced the realistic space, were better valued because the application used for the last phase (Enscape) is more focused on the realistic presentation of the object, in which light and shadows, the external environment and the realism of the materials, in addition to the other benefits of the IVR, complete the perception of the architectural spaces in a better way.

When the students entered the space that they themselves built in the IVR, they perceived the space in a superior way to that already experienced initially by seeing the 2D drawings; this is attributed to the fact that immersive virtual environments, through the visual dimension of perception, in combination with interactive feedback, generate immersion [11] that allowed them to better appreciate the characteristics of the space in a 
more realistic way. Contrary to this, little similarity was found with traditional drawing on paper, which may be due to the fact that the drawing courses studied at the university do not combine the actions of thinking, drawing and building, focusing on obtaining projections or mechanical representations of the architectural objects [5], and are far from developing creative thinking in which the eyes, the hands and the whole body work together holistically.

The variation of some sensations perceived in the realistic space constructed in IVR, despite a greater approximation in global terms to the sensations expressed by the experts, may be due to the fact that each individual perceives their environment in a unique way, subconsciously superimposing information to create something more complex than the physical space itself; in the same way, IVR creates a direct link between human perception and the spaces experienced by creating, as a result, its own "Perceptional Space" [49]. On the other hand, although it is true that, for academic purposes, sensations can be categorized, these are perceived as the sum of all of the characteristics in the IVR environment. The students stated that in their first experience with virtual reality they felt very pleased, excited and surprised, sensations typical of the experience that could affect their perception of space in that direction. Although people can focus their attention on capturing certain sensations, we are constantly processing much more sensory information than we are normally aware of.

The changes found in the predominant sensations after experiencing the realistic space in the IVR are due to characteristics of the technology. For example, the predominance of the sensation of freedom, although it was not expressed by the experts, can be explained by the immediate open environment, without barriers, almost infinite, with natural daylight that was shown to the participant in the experience. The change by the first-year students from the feeling of fragility/exposure to warmth/comfort can be explained by the realism of the wood, which makes the environments warm and comfortable. Finally, the change of the fifth-year students from emotion/spirituality to joy/theatricality can be explained by the property of immersion and presence that, together with the novelty of the experience using HMD (no student had used them before), generated the sensation of joy in the participants.

According to the students, the perception of the space created realistically and experienced in the IVR is more similar to the perception they had of the same space when they appreciated it based on 2D sketches rather than the perception of the space drawn and built by themselves in 3D. Considering that perception is a complex psychological process in which various mental and cognitive processes occur, we can understand that the space built by the students themselves, which did not have the ideal construction precision or the realistic representation of the materials, and lacked natural lighting and a well-defined environment, resulted in an incomplete perception and was therefore not so similar to that experienced in realistic space.

The research brings an important methodological implication, that the IVR must be incorporated into the learning process of drawing, design and perception of architectural spaces in such a way that the paradigm of drawing and design based on two-dimensional graphics will be broken. Then, we will be able to take an important leap towards the naturalness of drawing, design and perception in virtual worlds similar to the real one. Even so, there are also practical implications, such as the abandonment of the two-dimensional freehand drawing for the three-dimensional drawing that ends up becoming a threedimensional design. Perhaps we are witnessing the end of two-dimension drawing.

Finally, in a previous study [48] the research team concluded that spatial skills (including mental rotation and spatial orientation) can be trained with the drawing of architectural spaces at full scale in IVR. The training required not only spatial cognitive processes but also motor skills, because they were drawings larger than the person. It is evident that the drawing of objects larger than the draftsman requires different motor skills than those required when drawing on a sheet of paper. The influence of motor skills on the performance of the spatial skill tasks was demonstrated in the meta-analysis by Voyer and Jansen [47], 
so it will be necessary to study the motor and spatial skills that directly affect architectural drawing and design in IVR.

\section{Conclusions}

The perception of spaces, as a product of the observation of freehand drawings based on the indicators-domain, use and activity, measurements, construction materials and sensations-is high (70.8\%), which confirms the importance of two-dimensional drawings for the perception and experimentation of architectural spaces, i.e., they allow the observer to imagine living in the represented space as if it were almost real.

The precision of a space drawn three-dimensionally in the IVR is high $(83.9 \%)$; this was assessed based on the indicators, i.e., the measurements, scale, proportion, accuracy and materials of the drawn models; however, this precision did not extend to the mimetic and realistic representation of the object, but to three aspects: to a schematic representation with measurements, scale and proportions that allow the understanding and perception of the architectural space; to a complete representation of the different walls, ceilings and floors that define the spaces; and to a representation that somehow expresses the materiality of the object. In this way, it was concluded that the freehand drawing tool in 3D and in the IVR is suitable not only for the drawing of the initial and conceptual ideas of the design but also for the drawing and development of the ideas that give rise to the architectural party.

The high utility of freehand drawing in 3D and in the IVR that students found to capture the initial ideas of the design, to explore the spaces, and to draw and design architecture, and the high realism experienced in the environment of the IVR allowed us to conclude that it is a tool of great potential for the study and learning of architectural drawing and design in the first years of a professional career.

As for the qualities recognized by the scientific community that are attributed to the IVR, such as immersion and presence, the possibility of visualizing and knowing the three dimensions of the object and the realism that illumination, the environment and the materials give it, we conclude that it is the real or natural scale in which spaces can be experienced that is the most important characteristic in the field of architectural drawing and design and its learning.

The perception of the sensations evoked by the space on the observers was closer to that expressed by the experts when the students experienced the realistically constructed space in the IVR than when they perceived it based on 2D sketches [48]. However, the results do not allow us to reliably conclude the best perception of sensations in IVR.

An important limitation was the restrictive government regulations on mobility due to the Covid-19 Pandemic, which did not allow the recruitment of a larger number of participants for the study. Finally, this research proposes as a future research line a comparative study with a larger sample between the perception of real spaces (digitally manufactured) and the perception of the same space in the IVR using portable devices capable of capturing brain waves that give us a more objective approximation of the sensations perceived to be contrasted with those expressed in questionnaires.

Author Contributions: Conceptualization, H.C.G.-T. and J.M.-G.; Data curation, J.B.E. and P.B.E.; Formal analysis, H.C.G.-T., J.B.E., P.B.E. and J.M.-G.; Methodology, H.C.G.-T. and J.M.-G.; Resources, H.C.G.-T. and J.M.-G.; Software, J.B.E. and P.B.E.; Supervision, H.C.G.-T. and J.M.-G.; Validation, H.C.G.-T., J.B.E. and J.M.-G.; Visualization, P.B.E.; Writing-original draft, J.B.E. and P.B.E.; Writingreview and editing, H.C.G.-T., J.B.E., P.B.E. and J.M.-G. All authors have read and agreed to the published version of the manuscript.

Funding: This research was funded by Universidad Nacional de San Agustín de Arequipa, grant number IBA-IB-01-2019-UNSA.

Informed Consent Statement: Informed consent was obtained from all subjects involved in the study.

Data Availability Statement: The data presented in this study are available on request from the corresponding author. 
Acknowledgments: Thanks to the students of the Universidad Nacional de San Agustín de Arequipa (Peru) for their generous participation in this study.

Conflicts of Interest: The authors declare no conflict of interest.

\section{Appendix A. Questionnaires 1, 2 and 3}

Questionary 1: Perception of space based on 2D sketches

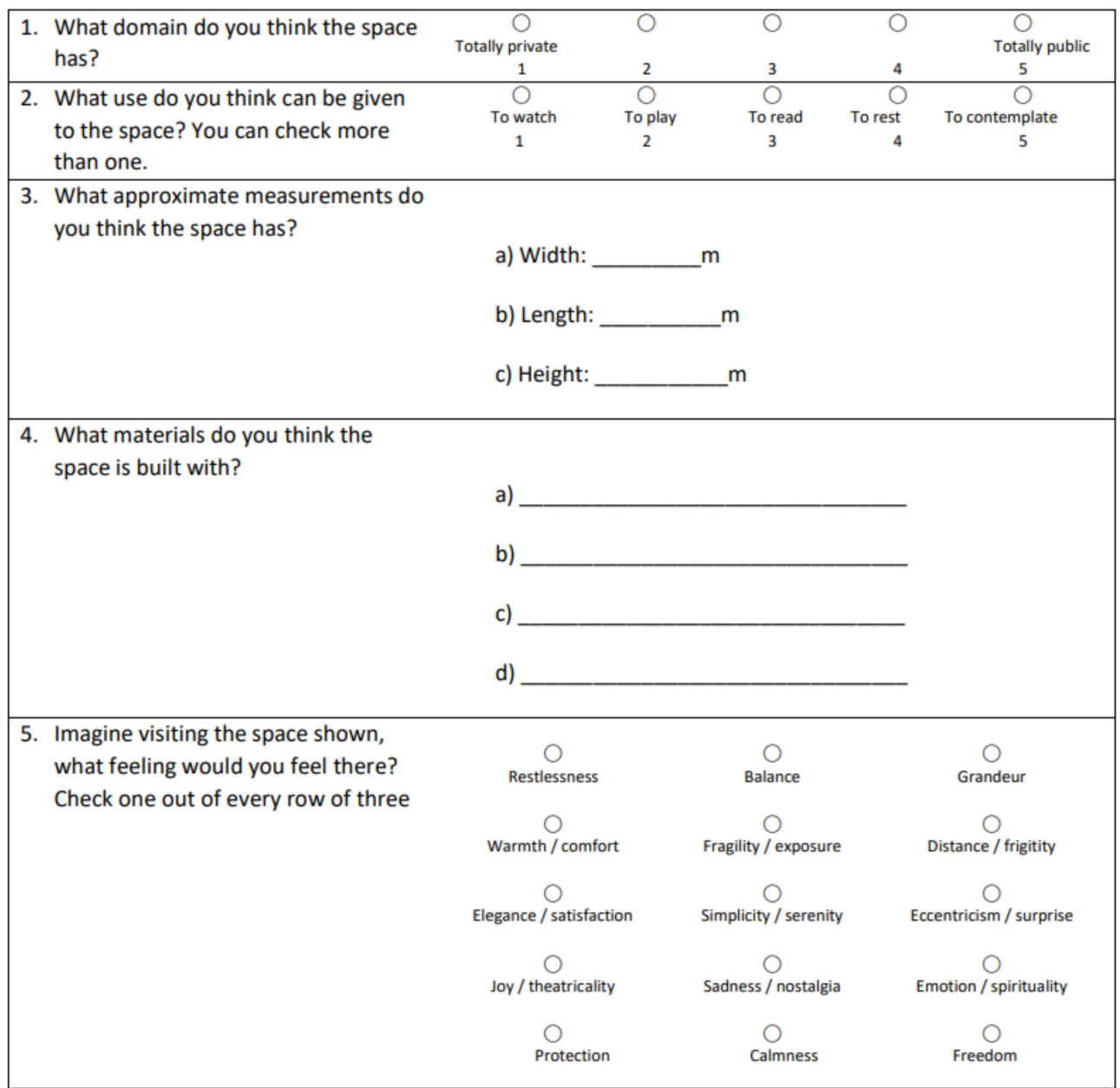


Questionary 2: Perception of space drawn in 3D in IVR

\begin{tabular}{|c|c|c|c|c|c|}
\hline $\begin{array}{l}\text { 1. How much do you think 3D freehand } \\
\text { drawing could help you capture initial } \\
\text { design ideas? }\end{array}$ & $\begin{array}{c}\text { O } \\
\text { Nothing } \\
1\end{array}$ & O & $\mathrm{O}$ & O & $\begin{array}{c}\text { O } \\
\text { Much } \\
5\end{array}$ \\
\hline $\begin{array}{l}\text { 2. How much would you recommend } \\
\text { using the tool for architectural design } \\
\text { ? }\end{array}$ & $\begin{array}{c}\text { Oothing } \\
1\end{array}$ & O & 0 & 0 & $\begin{array}{c}\text { O } \\
\text { Much } \\
5\end{array}$ \\
\hline $\begin{array}{l}\text { 3. } 3 \text { How attractive was the use of the } \\
\text { tool for exploring architectural } \\
\text { spaces? }\end{array}$ & $\begin{array}{c}\text { O } \\
\text { Nothing } \\
1\end{array}$ & $\mathrm{O}$ & $\mathrm{O}$ & O & $\begin{array}{l}\text { O } \\
\text { Much } \\
5\end{array}$ \\
\hline $\begin{array}{l}\text { 4. How much would you recommend } \\
\text { using the tool for architectural } \\
\text { drawing ? }\end{array}$ & $\begin{array}{c}\text { O } \\
\text { Nothing } \\
1\end{array}$ & 0 & 0 & 0 & $\begin{array}{c}\mathrm{O} \\
\text { Much } \\
5\end{array}$ \\
\hline $\begin{array}{l}\text { 5. How realistic is the space given the } \\
\text { possibility of entering it? }\end{array}$ & $\begin{array}{c}\text { O } \\
\text { Nothing } \\
1\end{array}$ & 0 & 0 & 0 & $\begin{array}{c}\text { O } \\
\text { Much } \\
5\end{array}$ \\
\hline $\begin{array}{l}\text { 6. How realistic is the space given its } \\
\text { perception in real size? }\end{array}$ & $\begin{array}{c}\text { O } \\
\text { Nothing } \\
1\end{array}$ & 0 & 0 & O & $\begin{array}{l}\bigcirc \\
\text { Much } \\
5\end{array}$ \\
\hline $\begin{array}{l}\text { 7. How much realism gives space the } \\
\text { possibility of looking everywhere? }\end{array}$ & $\begin{array}{c}\text { O } \\
\text { Nothing } \\
1\end{array}$ & 0 & 0 & 0 & $\begin{array}{c}\mathrm{O} \\
\text { Much } \\
5\end{array}$ \\
\hline $\begin{array}{l}\text { 8. How much realism does light and } \\
\text { shadows give the space? }\end{array}$ & $\begin{array}{c}\text { Nothing } \\
1\end{array}$ & 0 & 0 & 0 & $\begin{array}{l}\bigcirc \\
\text { Much } \\
5\end{array}$ \\
\hline $\begin{array}{l}\text { 9. How much realism do the materials } \\
\text { used give the space? }\end{array}$ & $\begin{array}{c}\text { O } \\
\text { Nothing } \\
1\end{array}$ & 0 & 0 & O & $\begin{array}{l}\mathrm{O} \\
\text { Much } \\
5\end{array}$ \\
\hline $\begin{array}{l}\text { 10. How much realism does the } \\
\text { environment or external environment } \\
\text { give the space? }\end{array}$ & $\begin{array}{c}\text { Nothing } \\
1\end{array}$ & 0 & 0 & O & $\begin{array}{c}\text { Much } \\
5\end{array}$ \\
\hline $\begin{array}{l}\text { 11. Mention two advantages that you } \\
\text { consider that freehand drawing in 3D } \\
\text { has compared to drawing also in 3D } \\
\text { but on a computer with programs } \\
\text { such as SketchUp or similar }\end{array}$ & $\begin{array}{l}\text { Advantage 1: } \\
\text { Advantage 2: }\end{array}$ & & & & \\
\hline $\begin{array}{l}\text { 12. Mention two disadvantages that you } \\
\text { consider that freehand drawing in 3D } \\
\text { has compared to drawing also in 3D } \\
\text { but on a computer with programs } \\
\text { such as SketchUp or similar }\end{array}$ & Disadvantage 1: & & & & \\
\hline $\begin{array}{l}\text { 13. When you entered the space that you } \\
\text { drew in } 3 D \text {, how similar was your } \\
\text { perception of that space compared to } \\
\text { your initial perception of the same } \\
\text { space drawn in 2D? }\end{array}$ & $\begin{array}{c}\mathrm{O} \\
\text { Nothing similar } \\
1\end{array}$ & 0 & 0 & 0 & $\begin{array}{c}\mathrm{O} \\
\text { Very similar } \\
5\end{array}$ \\
\hline $\begin{array}{l}\text { 14. In general terms, how real have you } \\
\text { perceived the virtual world? }\end{array}$ & $\begin{array}{l}\bigcirc \\
\text { Nothing real } \\
1\end{array}$ & O & O & O & $\begin{array}{c}\bigcirc \\
\text { Very real } \\
5\end{array}$ \\
\hline $\begin{array}{l}\text { 15. How similar do you find the action of } \\
\text { drawing in } 3 D \text { compared to the action } \\
\text { of drawing in } 2 D \text { ? }\end{array}$ & $\begin{array}{c}\bigcirc \\
\text { Nothing similar } \\
1\end{array}$ & O & 0 & 0 & $\begin{array}{l}\mathrm{O} \\
\text { Very similar } \\
5\end{array}$ \\
\hline $\begin{array}{l}\text { 16. How comfortable was the experience } \\
\text { of freehand drawing in } 3 D\end{array}$ & $\begin{array}{l}\mathrm{O} \\
\text { Not at all comfortable } \\
1\end{array}$ & O & 0 & 0 & $\begin{array}{l}\bigcirc \\
\text { Very comfortable } \\
5\end{array}$ \\
\hline $\begin{array}{l}\text { 17. How easy was it to draw a life-size } \\
\text { architectural space? }\end{array}$ & $\begin{array}{l}\bigcirc \\
\text { Not easy } \\
1\end{array}$ & O & 0 & 0 & $\begin{array}{c}0 \\
\text { Very easy } \\
5\end{array}$ \\
\hline $\begin{array}{l}\text { 18. How much precision do you think you } \\
\text { achieved in the final } 3 D \text { result? }\end{array}$ & $\begin{array}{c}\mathrm{O} \\
\text { No precision } \\
1\end{array}$ & 0 & 0 & 0 & $\begin{array}{l}\mathrm{O} \\
\text { High precision } \\
5\end{array}$ \\
\hline
\end{tabular}


Questionary 3: Perception of the same space realistically modeled in 3D in IVR

\begin{tabular}{|c|c|c|c|c|c|}
\hline \multirow{2}{*}{$\begin{array}{l}\text { 1. How much realism does space give the } \\
\text { possibility of entering it? }\end{array}$} & $\underset{\text { Nothing }}{\bigcirc}$ & $\mathrm{O}$ & $\mathrm{O}$ & $\mathrm{O}$ & $\underset{\text { Much }}{\bigcirc}$ \\
\hline & 1 & 2 & 3 & 4 & 5 \\
\hline \multirow{2}{*}{$\begin{array}{l}\text { 2. How much realism does the space give } \\
\text { its real size? }\end{array}$} & $\begin{array}{c}\mathrm{O} \\
\text { Nothing }\end{array}$ & $\mathrm{O}$ & $\mathrm{O}$ & $\mathrm{O}$ & $\underset{\text { Much }}{\bigcirc}$ \\
\hline & 1 & 2 & 3 & 4 & 5 \\
\hline \multirow{2}{*}{$\begin{array}{l}\text { 3. How much realism gives space the } \\
\text { possibility of looking everywhere? }\end{array}$} & $\underset{\text { Nothing }}{\mathrm{O}}$ & $\mathrm{O}$ & $\mathrm{O}$ & $\mathrm{O}$ & $\underset{\text { Much }}{\bigcirc}$ \\
\hline & 1 & 2 & 3 & 4 & 5 \\
\hline \multirow{2}{*}{$\begin{array}{l}\text { 4. How much realism does light and } \\
\text { shadows give the space? }\end{array}$} & $\begin{array}{c}\mathrm{O} \\
\text { Nothing }\end{array}$ & $\mathrm{O}$ & $\mathrm{O}$ & $\mathrm{O}$ & $\underset{\text { Much }}{O}$ \\
\hline & 1 & 2 & 3 & 4 & 5 \\
\hline \multirow{2}{*}{$\begin{array}{l}\text { 5. How much realism do the materials } \\
\text { used give the space? }\end{array}$} & $\begin{array}{c}\mathrm{O} \\
\text { Nothing }\end{array}$ & $\mathrm{O}$ & $\mathrm{O}$ & $\mathrm{O}$ & $\underset{\text { Much }}{\bigcirc}$ \\
\hline & 1 & 2 & 3 & 4 & 5 \\
\hline \multirow{2}{*}{$\begin{array}{l}\text { 6. How much realism does the } \\
\text { environment or external environment } \\
\text { give the space? }\end{array}$} & $\underset{\text { Nothing }}{\bigcirc}$ & $\mathrm{O}$ & $\mathrm{O}$ & $\mathrm{O}$ & $\underset{\text { Much }}{\bigcirc}$ \\
\hline & 1 & 2 & 3 & 4 & 5 \\
\hline \multirow{6}{*}{$\begin{array}{l}\text { 7. Order the next characteristics } \\
\text { according to the realism they give the } \\
\text { space. Put one to the most important } \\
\text { and six to the most irrelevant: }\end{array}$} & ) Wal & oof & aterials & & \\
\hline & ) The & bility & entering space & & \\
\hline & ) The & bility & looking everywh & & \\
\hline & ) Scal & Jal s & & & \\
\hline & ) The & $\mathrm{nm}$ & (the external en & ironment) & \\
\hline & ) Ligh & shad & & & \\
\hline \multirow{2}{*}{$\begin{array}{l}\text { 8. How similar do you perceive this } \\
\text { virtual space compared to } 2 \mathrm{D} \text { drawing? }\end{array}$} & Nothing & 0 & $\mathrm{O}$ & $\mathrm{O}$ & $\underset{\text { Much }}{\bigcirc}$ \\
\hline & 1 & 2 & 3 & 4 & 5 \\
\hline \multirow{2}{*}{$\begin{array}{l}\text { 9. How similar do you perceive this } \\
\text { virtual space compared to } 3 \mathrm{D} \text { drawing? }\end{array}$} & $\underset{\text { Nothing }}{O}$ & $\mathrm{O}$ & $\mathrm{O}$ & $\mathrm{O}$ & $\underset{\text { Much }}{\bigcirc}$ \\
\hline & 1 & 2 & 3 & 4 & 5 \\
\hline \multirow[t]{5}{*}{$\begin{array}{l}\text { 10.What feeling do you feel now? Check } \\
\text { one out of each row of three }\end{array}$} & $\underset{\text { Restles: }}{\bigcirc}$ & & $\underset{\text { Balance }}{\bigcirc}$ & $\mathrm{Gr}$ & andeur \\
\hline & Warmth / & & $\stackrel{\bigcirc}{\text { Fragility / exposure }}$ & Distanc & $\begin{array}{l}\text { e / frigitity } \\
\text { (n) }\end{array}$ \\
\hline & Elegance $/ \mathrm{s}$ & & Simplicity / serenity & Eccentricism & $\overbrace{1 / \text { surprise }}$ \\
\hline & Joy/thea & & $\bigcirc_{\text {sadness / nostalgia }}^{\bigcirc}$ & tmotion / & $\mathrm{O}_{\text {spirituality }}$ \\
\hline & & & Calmness & & edom \\
\hline
\end{tabular}

\section{References}

1. Tversky, B.; Suwa, M.; Agrawala, M.; Heiser, J.; Stolte, C.; Hanrahan, P.; Phan, D.; Klingner, J.; Daniel, M.-P.; Lee, P.; et al. Sketches for design and design of sketches. In Human Behaviour in Design: Individuals, Teams, Tools; Lindemann, U., Ed.; Springer: Berlin/Heidelberg, Germany, 2003; pp. 79-86. ISBN 978-3-662-07811-2.

2. Sandnes, F.E. Sketching 3D immersed experiences rapidly by hand through 2D cross sections. In Online Engineering $\mathcal{E}$ Internet of Things; Auer, M.E., Zutin, D.G., Eds.; Springer International Publishing: Cham, Switzerland, 2018; Volume 22, pp. 1001-1013. ISBN 978-3-319-64351-9.

3. Suwa, M.; Tversky, B. What do architects and students perceive in their design sketches? A protocol analysis. Des. Stud. 1997, 18, 385-403. [CrossRef]

4. Suwa, M.; Gero, J.; Purcell, T. Unexpected discoveries and s-invention of design requirements: Important vehicles for a design process. Des. Stud. 2000, 21, 539-567. [CrossRef]

5. Seguí de la Riva, F.J. Proyectar, proyecto; dibujar, dibujo. EGA Expr. Gráfica Arquit. 2018, 23, 56-73. [CrossRef]

6. Trachana, A. Manual or digital. Anthropological foundations of architectural drawing and building models. Ega-Rev. Expr. Graf. Arquit. 2012, 288-297.

7. Deleuze, G. Pintura: El Concepto de Diagrama; Cactus: Buenos Aires, Argentina, 2008; ISBN 987-21000-9-8.

8. Esteban, S.I. El croquis como vehículo de la experiencia arquitectónica. Constel. Rev. Arquit. Univ. CEU San Pablo Archit. Mag. CEU San Pablo Univ. 2015, 3, 189-200.

9. Maier, J.R.A.; Fadel, G.M.; Battisto, D.G. An affordance-based approach to architectural theory, design, and practice. Des. Stud. 2009, 30, 393-414. [CrossRef]

10. Gomes, R.; Aquilué, I.; Roca, E. Cuerpo, espacio y el dibujo arquitectónico. ACE Archit. City Environ. 2017, 12. [CrossRef] 
11. Hermund, A.; Klint, L.S.; Bundgaard, T.S. The perception of architectural space in reality, in virtual reality, and through plan and section drawings. In Proceedings of the Computing for a Better Tomorrow, Łódź, Poland, 19-21 September 2018; Volume 2, pp. 735-744.

12. Tsou, C.-H.; Hsu, T.-W.; Lin, C.-H.; Tsai, M.-H.; Hsu, P.-H.; Lin, I.-C.; Wang, Y.-S.; Lin, W.-C.; Chuang, J.-H. Immersive VR Environment for Architectural Design Education. In Proceedings of the SIGGRAPH Asia 2017 Posters on-SA '17, Bangkok, Thailand, 27-30 November 2017; ACM Press: Bangkok, Thailand, 2017; pp. 1-2.

13. Alatta, R.A.; Freewan, A. Investigating the Effect of Employing Immersive Virtual Environment on Enhancing Spatial Perception within Design Process. ArchNet-IJAR Int. J. Archit. Res. 2017, 11, 219. [CrossRef]

14. Pallasmaa, J. The Thinking Hand: Existential and Embodied Wisdom in Architecture; Wiley Chichester: Chichester, UK, 2009; ISBN 0-470-77928-4.

15. Gomes, R. Design, drawing and the teaching of architecture through corporeality. Arquiteturarevista 2016, 12, 36.

16. Öktem Erkartal, P.; Ökem, H.S. The phenomenon of touch in architectural design and a field study for haptic mapping. Megaron Yildiz Tech. Univ. Fac. Archit. E-J. 2015, 10, 92-111. [CrossRef]

17. Israel, J.H.; Wiese, E.; Mateescu, M.; Zöllner, C.; Stark, R. Investigating three-dimensional sketching for early conceptual design-Results from expert discussions and user studies. Comput. Graph. 2009, 33, 462-473. [CrossRef]

18. Fieandt, K.; Järvinen, E.; Korkala, P. Space perception. Encyclopedia Britannica. 2007. Available online: https://www.britannica. com/science/space-perception (accessed on 24 May 2021).

19. Rasmussen, S.E. La Experiencia de La Arquitectura; Reverté: Barcelona, Spain, 2004; Volume 5, ISBN 84-291-2105-6.

20. Angulo, A. On the design of architectural spatial experiences using immersive simulation. In Proceedings of the EAEA 11 Conference Proceedings, Envisioning Architecture: Design, Evaluation, Communication, Milan, Italy, 25-28 September 2013; pp. 151-158.

21. Roberts, G.; Holmes, N.; Alexander, N.; Boto, E.; Leggett, J.; Hill, R.M.; Shah, V.; Rea, M.; Vaughan, R.; Maguire, E.A.; et al. Towards OPM-MEG in a virtual reality environment. NeuroImage 2019, 199, 408-417. [CrossRef]

22. Shemesh, A.; Talmon, R.; Karp, O.; Amir, I.; Bar, M.; Grobman, Y.J. Affective response to architecture-investigating human reaction to spaces with different geometry. Archit. Sci. Rev. 2017, 60, 116-125. [CrossRef]

23. Ergan, S.; Radwan, A.; Zou, Z.; Tseng, H.; Han, X. Quantifying human experience in architectural spaces with integrated virtual reality and body sensor networks. J. Comput. Civ. Eng. 2019, 33, 04018062. [CrossRef]

24. Yeom, D.; Choi, J.-H.; Kang, S.-H. Investigation of the physiological differences in the immersive virtual reality environment and real indoor environment: Focused on skin temperature and thermal sensation. Build. Environ. 2019, 154, 44-54. [CrossRef]

25. Kuliga, S.F.; Thrash, T.; Dalton, R.C.; Hölscher, C. Virtual reality as an empirical research tool—exploring user experience in a real building and a corresponding virtual model. Comput. Environ. Urban Syst. 2015, 54, 363-375. [CrossRef]

26. Homolja, M.; Maghool, S.A.H.; Schnabel, M.A. The impact of moving through the built environment on emotional and neurophysiological state-A systematic literature review. In Proceedings of the 25th International Conference of the Association for Computer-Aided Architectural Design Research in Asia (CAADRIA), Bangkok, Thailand, 5-6 August 2020; Volume 1, pp. 641-650.

27. Maghool, S.A.H.; Homolja, M.; Schnabel, M.A. Cybernetics approach to virtual emotional spaces-An electrodermal activity actuated adaptive space. In Proceedings of the 38th Conference of Education and Research in Computer Aided Architectural Design in Europe (eCAADe), Berlin, Germany, 16-18 September 2020; Volume 1, pp. 537-546.

28. Keil, J.; Edler, D.; O'Meara, D.; Korte, A.; Dickmann, F. Effects of virtual reality locomotion techniques on distance estimations. ISPRS Int. J. Geo-Inf. 2021, 10, 150. [CrossRef]

29. Boletsis, C.; Cedergren, J.E. VR Locomotion in the new era of virtual reality: An empirical comparison of prevalent techniques. Adv. Hum.Comput. Interact. 2019, 2019. [CrossRef]

30. Lokka, I.E.; Çöltekin, A. Toward optimizing the design of virtual environments for route learning: Empirically assessing the effects of changing levels of realism on memory. Int. J. Digit. Earth 2019, 12, 137-155. [CrossRef]

31. Novoa, M. Do We need a new theory of drawing? Exploration on technological change between physical and digital visualisation. In Proceedings of the 21st International Conference on Engineering and Product Design Education (E\&PDE 2019), Glasgow, Scotland, 12-13 September 2019.

32. Yang, E.K.; Lee, J.H. Cognitive impact of virtual reality sketching on designers' concept generation. Digit. Creat. 2020, 82-97. [CrossRef]

33. Milovanovic, J.; Moreau, G.; Siret, D.; Miguet, F. Virtual and augmented reality in architectural design and education. In Proceedings of the 17th International Conference, CAAD Futures, Istanbul, Turkey, 12-14 July 2017.

34. Gandotra, S.; Pungotra, H. Tools and Techniques for conceptual design in virtual reality environment. Manag. J. Future Eng. Technol. 2017, 12, 8.

35. Zhang, L.-F. Thinking styles and cognitive development. J. Genet. Psychol. 2002, 163, 179-195. [CrossRef]

36. Alba Dorado, M.I. Manos que piensan. Reflexiones acerca del proceso creativo del proyecto de arquitectura. EGA Expr. Gráfica Arquit. 2013, 18, 196-203. [CrossRef]

37. López Belmonte, J.; Pozo Sánchez, S.; Morales Cevallos, M.B.; López Meneses, E. Competencia digital de futuros docentes para efectuar un proceso de enseñanza y aprendizaje mediante realidad virtual. Edutec. Rev. Electrónica Tecnol. Educ. 2019, 67, 1237. [CrossRef] 
38. Leiva Olivencia, J.J.; Moreno Martínez, N.M. Recursos y estrategias educativas basadas en el uso de hardware de bajo coste y software libre: Una perspectiva pedagógica intercultural. Migramos Una Nueva Plataforma 2015, 15, 37-50. [CrossRef]

39. Hermund, A.; Bundgaard, T.S.; Klint, L.S. Speculations on the representation of architecture in virtual reality: How can we (continue to) simulate the unseen? In Proceedings of the 51st International Conference of the Architectural Science Association (ANZAScA), Wellington, New Zealand, 27 November-2 December 2017; p. 10.

40. Osterrieth, P.A. Le Test de Copie d'une Figure Complexe; Contribution à l'étude de La Perception et de La Mémoire. [Test of Copying a Complex Figure; Contribution to the Study of Perception and Memory. Arch. Psychol. 1944, 30, 206-356.

41. Kennedy, R.S.; Lane, N.E.; Berbaum, K.S.; Lilienthal, M.G. Simulator sickness questionnaire: An enhanced method for quantifying simulator sickness. Int. J. Aviat. Psychol. 1993, 3, 203-220. [CrossRef]

42. Kennedy, R.S.; Lane, N.E.; Lilienthal, M.G.; Berbaum, K.S.; Hettinger, L.J. Profile analysis of simulator sickness symptoms: Application to virtual environment systems. Presence Teleoperators Virtual Env. 1992, 1, 295-301. [CrossRef]

43. Lawson, B.D.; Graeber, D.A.; Mead, A.M.; Muth, E.R. Signs and symptoms human syndromes associated with synthetic experiences. In Human Factors and Ergonomics. Handbook of Virtual Environments: Design, Implementation, and Applications; Stanney, K.M., Ed.; Lawrence Erlbaum Associates Publishers: Mahwah, NJ, USA, 2002; pp. 589-618.

44. Kennedy, R.S.; Drexler, J.; Kennedy, R.C. Research in visually induced motion sickness. Appl. Ergon. 2010, 41, 494-503. [CrossRef]

45. Walter, H.; Li, R.; Munafo, J.; Curry, C.; Peterson, N.; Stoffregen, T. APAL coupling study 2019; University of Minnesota: Minneapolis, MN, USA, 2019. [CrossRef]

46. Barrera Machuca, M.D.; Stuerzlinger, W.; Asente, P. The effect of spatial ability on immersive 3D drawing. In Proceedings of the 2019 on Creativity and Cognition-C\&C '19, San Diego, CA, USA, 23-26 June 2019; ACM Press: San Diego, CA, USA, 2019; pp. 173-186.

47. Voyer, D.; Jansen, P. Motor expertise and performance in spatial tasks: A meta-analysis. Hum. Mov. Sci. 2017, 54, 110-124. [CrossRef] [PubMed]

48. Gómez-Tone, H.C.; Martin-Gutierrez, J.; Bustamante-Escapa, J.; Bustamante-Escapa, P. Spatial skills and perceptions of space: Representing 2D drawings as 3D drawings inside immersive virtual reality. Appl. Sci. 2021, 11, 1475. [CrossRef]

49. Holth, J.; Schnabel, M.A. Immersive virtual environments as a tool for exploring perceptional space. Int. J. Parallel Emergent Distrib. Syst. 2017, 32, S155-S162. [CrossRef] 